Journal of Business \& Management (COES\&RJ-JBM)

ISSN (E): 2306-7179 ISSN (P): 2306-8043

Publisher: Centre of Excellence for Scientific \& Research Journalism, COES\&RJ LLC

Online Publication Date \& Issue: 1st January 2017, Vol.5, No.1, January 2017

http://centreofexcellence.net/J/JBM/JBM\%20Mainpage.htm

\title{
Estimations Effect of the Forensic Accounting Role on the realized of the tax disputes resolution in Jordan

\author{
Dr. Abdulsattar A. Alkubaisi
}

\begin{abstract}
:
The study aimed to search in the estimations effect of the forensic accounting role on the realized resolution of tax disputes in Jordan according to the related parties points of view. The study population consisted of judges and forensic accountants regarding exploring estimations effect on the one hand, and the published data available about the size of realized for the years 2012 to 2015 (independent variables). The study, used the descriptive and analytical approach, using convenient statistical methods to analyze the data and abstracts conclusions and testing hypotheses, al that through the use of SPSS program, the most important result, There is a Big Gap between estimates and realization of forensic accounting role in the Dispute Resolution, The most important recommendation is, Necessity to find an integrate and adequate information system
\end{abstract}

Keywords:

Income and sales tax, Forensic accounting, Tax disputes, Tax estimations

\section{Citation:}

Alkubaisi, Dr. Abdulsattar A. (2017), Estimations Effect of the Forensic Accounting Role on the realized of the tax disputes resolution in Jordan ;Journal of Business \&

Management (COES\&RJ-JBM) Vol.5, No.1, pp.21-42

This work is licensed under a Creative Commons Attribution 4.0 International License. 
أثر التقليرات لاور المحاسبة القضائية على المتحقى في فصل القضايا الضريبة في الاردن

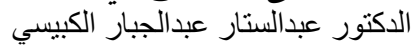

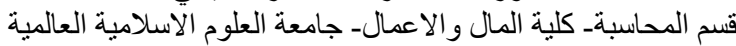

ملخص الدراسة

تهدف هذه الدر اسة الى البحث في أثر التقدير ات لدور المحاسبة القضائية على المتحقق في فصل القضايا الضريبية في

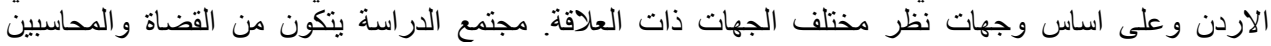

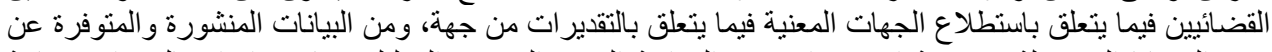

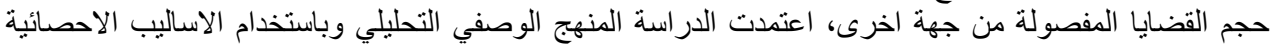

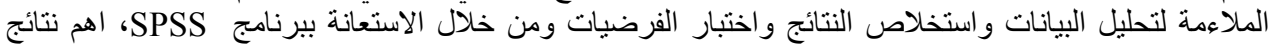

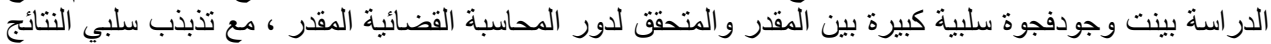

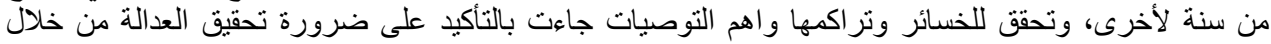

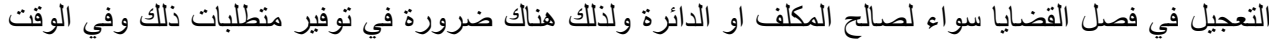

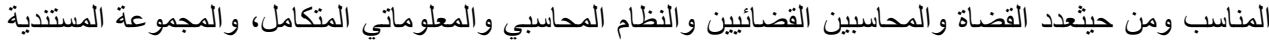
و الدفترية المتكاملة ضمن نظام معلومات متكامل يوفر المعلومات ت الهامة والمتطابقة للتخطيط و الرقابة و واتخاذ القرار ات السليمة.

الكلمات المفتاحية: ضريبة الاخل والمبيعات، المحاسبة القضائية، القضايا الضريبية، التقديرات الضريبية.

مقدمة

تشكل الاير ادات الضريبية وفي العالماجمع جزءا هاما وربما كبير اوحتى كبير ا جدا من الاير ادات العامة او من الناتج التهات المحلي الاجمالي، فهي في الولايات المتحدة الامريكية تشكل

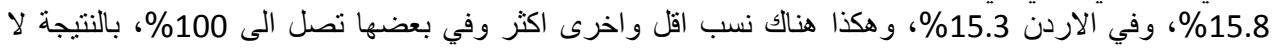

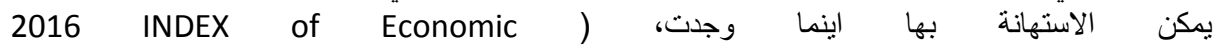
http://www.heritage.org/index/explore?view=by-variables. (Freedom

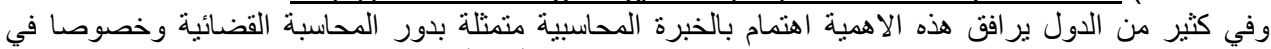

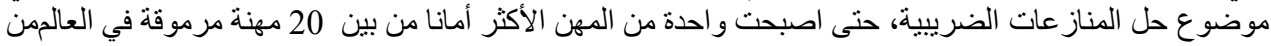

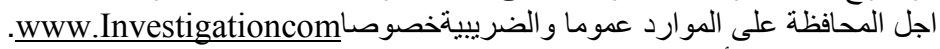

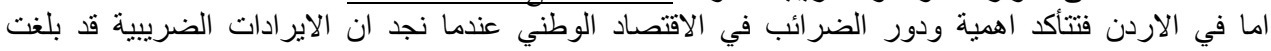

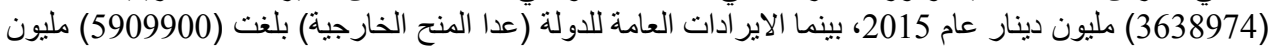

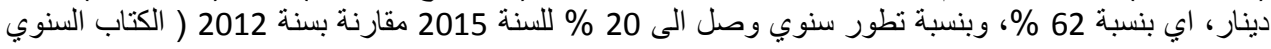

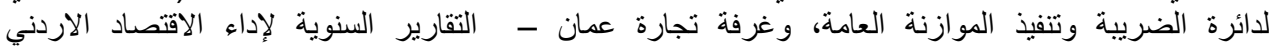

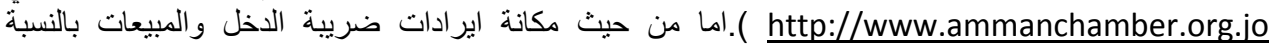

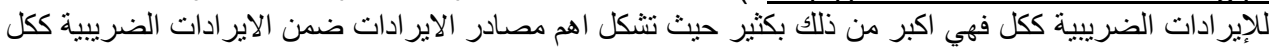

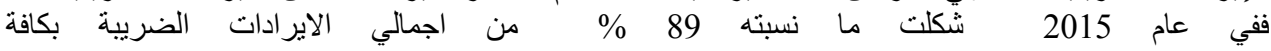

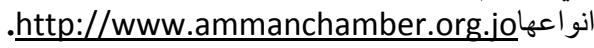
ومع ان الدولة في الاردن قد سعت الى تحقيق العدالة في فرض الضرائب وتحصيلها من خلال القوانين الخاصة

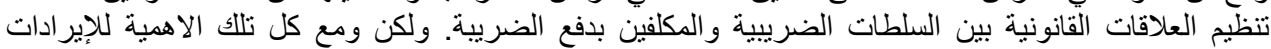

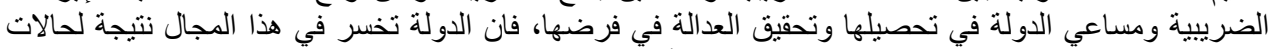

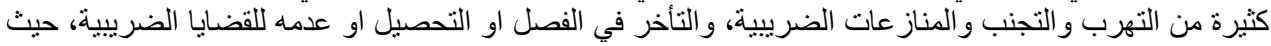

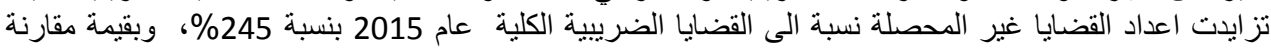
بسنة 2012, وازدادت قيمتها بنسبة 340 \% لنفس الفترة. وفي احسن الاحوال فان نسبة قيمة غير المفصولة او غير الفير

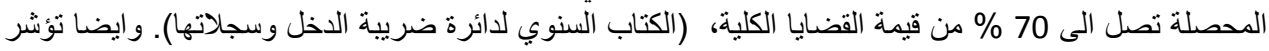

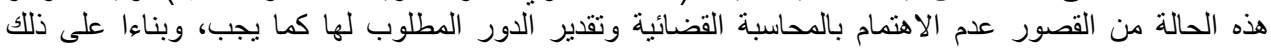

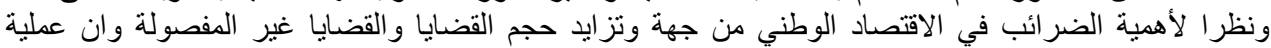

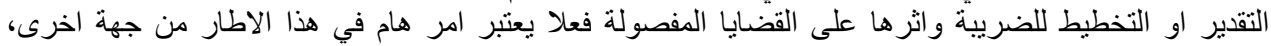

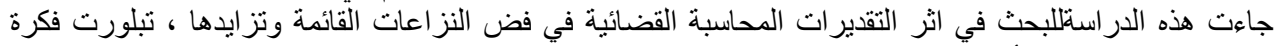

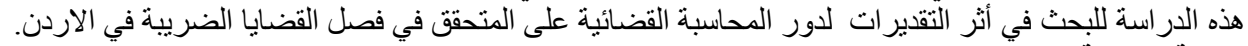
مشكلة الاراسة الإنة 


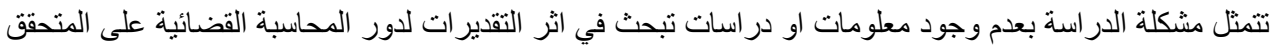

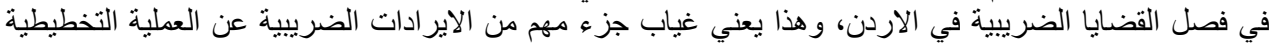

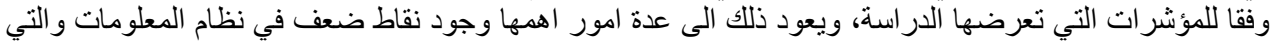

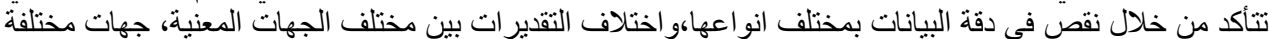
تقدم نفس نوع المعلومات ولفي ولكن مع تفاوت في دقتها.

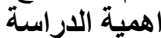

اهمية الدر اسة تتبلور من خلال الهميتها لأطر اف عديدة اهمها:

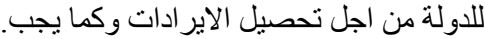
لائرة الضريبة للبحث في وجود نظام متكامل لتوفير المعلومات التوات المتطابقة المتكاملة وللتخطيط لمواردها وتهيئة

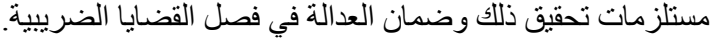

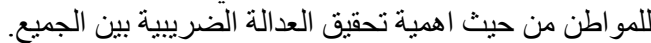

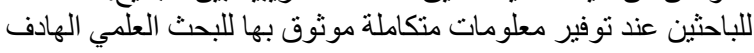

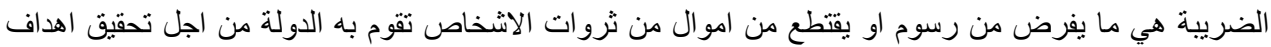

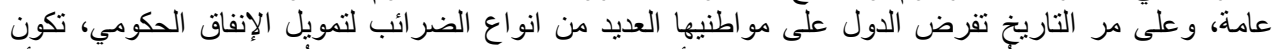

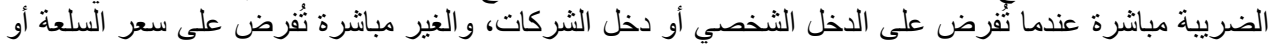

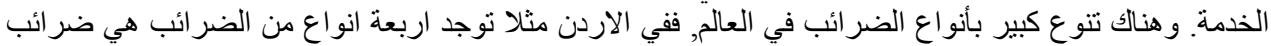

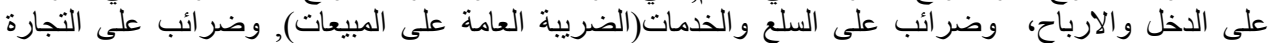

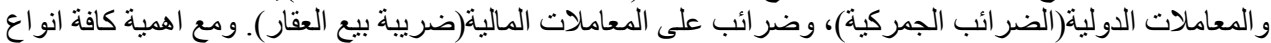

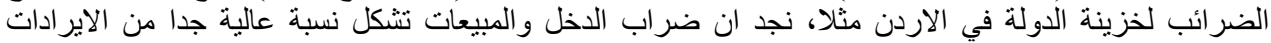
الضريبية مجتمعة, ففي عام 2015 بلغت اير ادات الضر الضرائب الكلية 4096 مليون دينار، منها

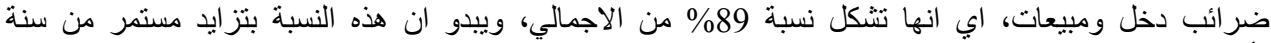

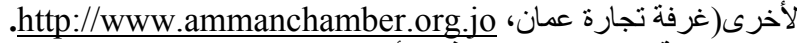
دائرة ضريبة الاخل والمبيعات في الأردن

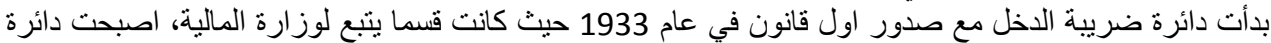

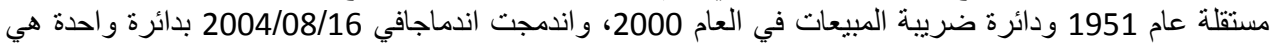

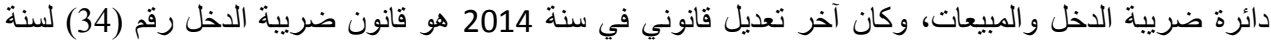

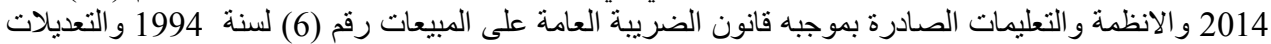

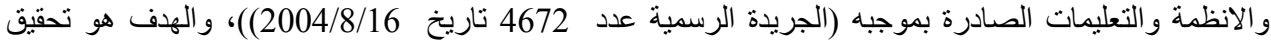

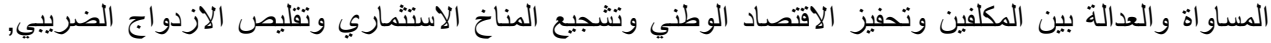

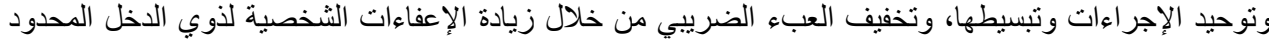

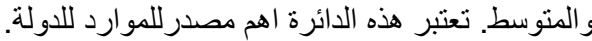

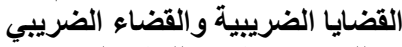

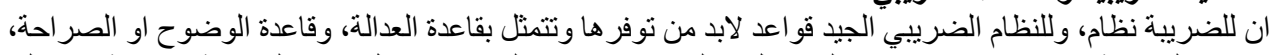

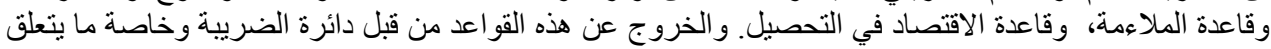

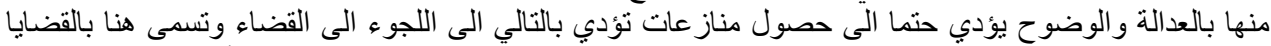

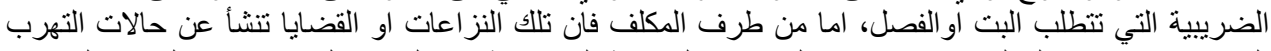

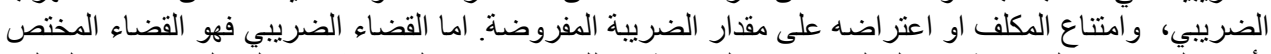

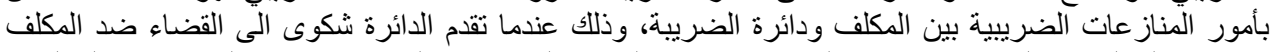

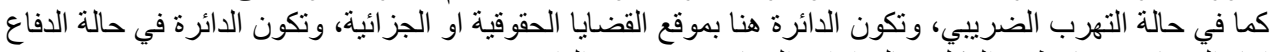

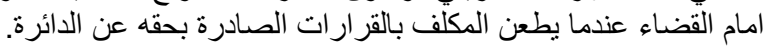

الاقرارات الضريبية

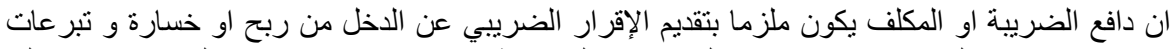

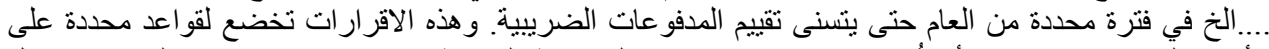

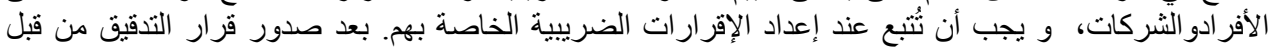

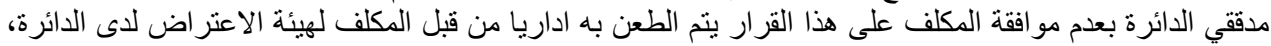




\section{Estimations Effect of the Forensic Accounting}

وبعد نظر هيئة الاعتر اض في قرار المدقق و المو افقة على ما جاء في هذا القرار يحق للمكلف اللجوء لمحكمة البداية الضريبية للفصل في القضية.

التقديرات الضريبية

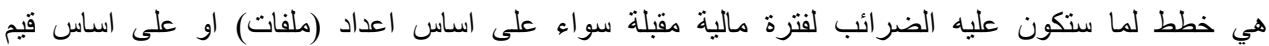

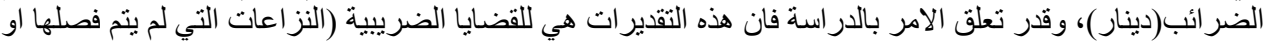

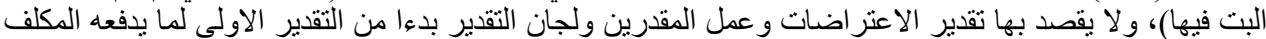

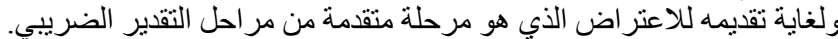

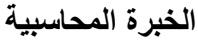

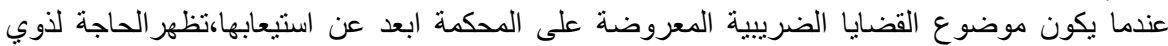

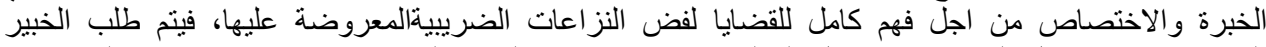

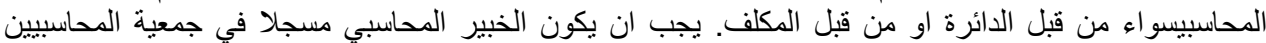
وتنطبق عليه الثروط القانونية الخاصة بالخبرة(نظام الخبرة امام المحاكم النظامية وتعديلاته رقم (78) لسنة 2001).

TADAT منهجية

تعمل دائرة ضريبة الدخل و المبيعات على تطبيق هذه المنهجية، وهي اداة تقييم وتنخيص الادارة الضريبية طورها

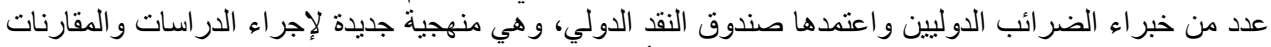

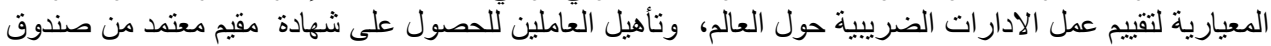

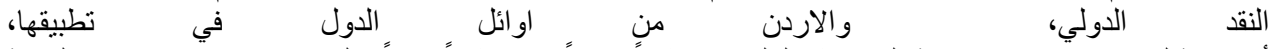

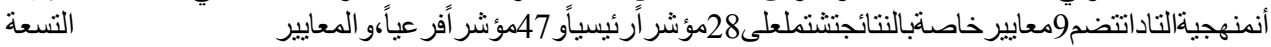

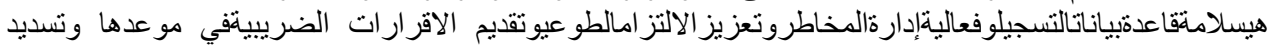

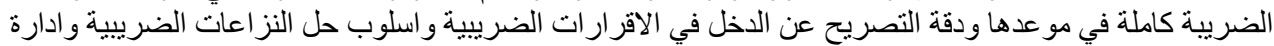
الاير ادات و المساءلة و الثفافية.

ثانيا: المحاسبة القضائية

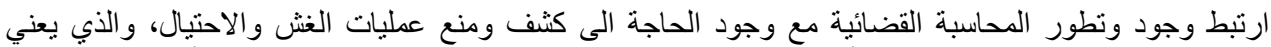

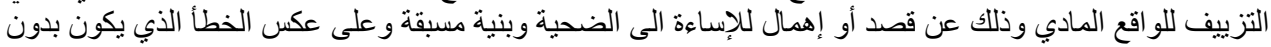

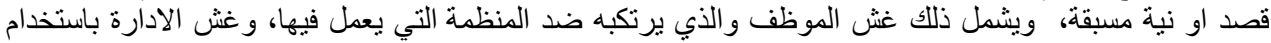

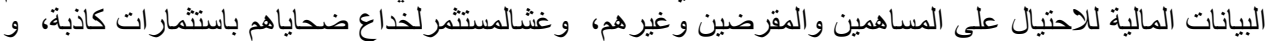

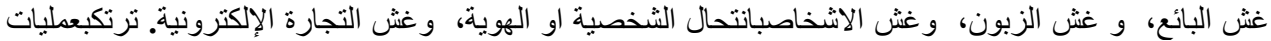

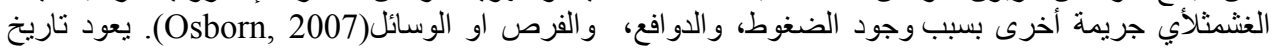

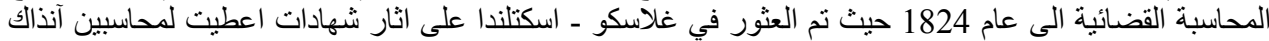

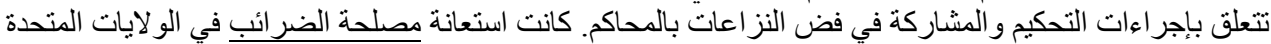

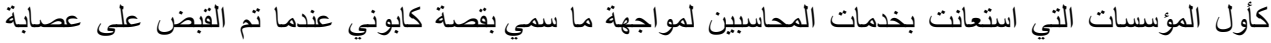

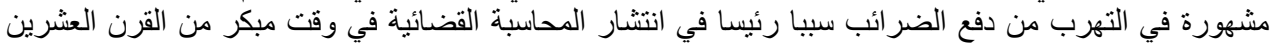

Frunkly, 2001))

والتعريف

المفهوم

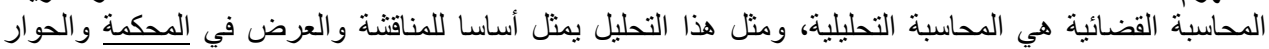

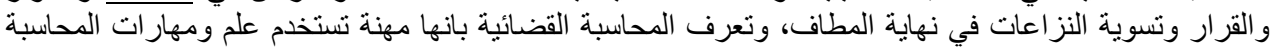

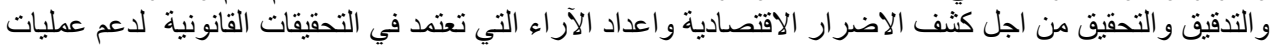

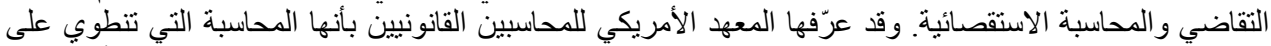

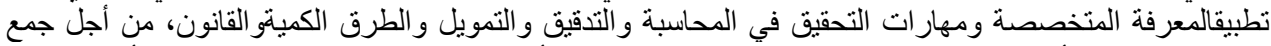

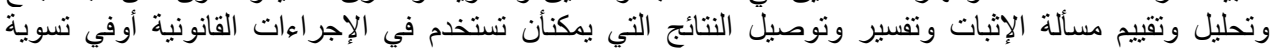

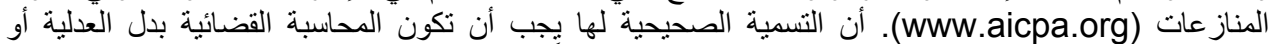

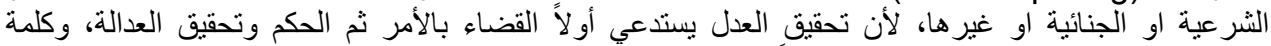

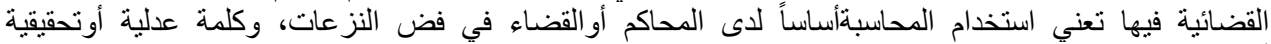

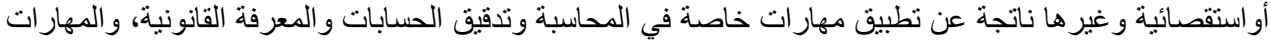

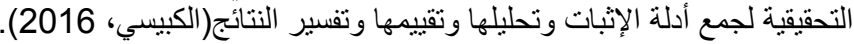

ت ت ت اخل وتكامل المهام

التكامل بين المحاسبة والتدقيق و التحقيق يمثل غلة او حصيلة المهارات المتخصصة المعروفة باسم المحاسبة القضائية

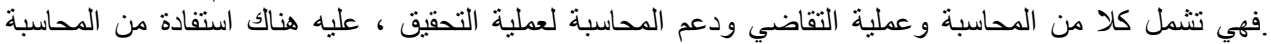

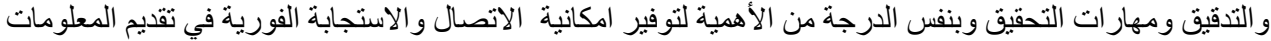

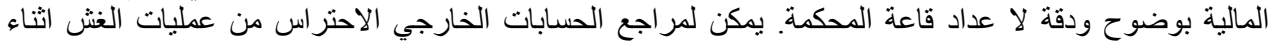


عمليات التدقيق الدورية. مع ان مهنة مر اجعة الحسابات اتخذت موقف مفاده أنه ليس من مسؤولية مدقق الحسابات

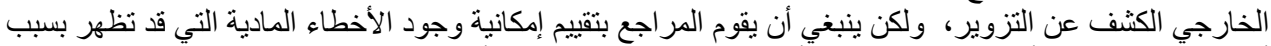

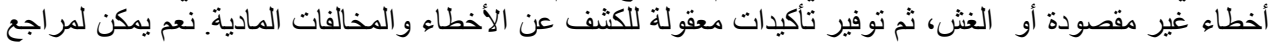

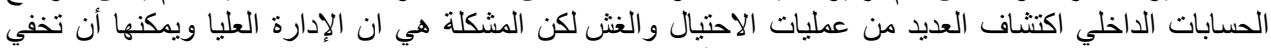

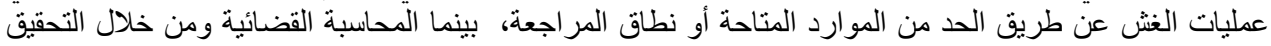

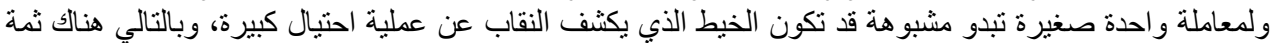

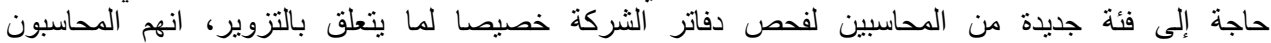

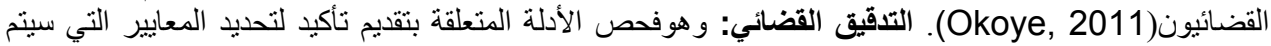

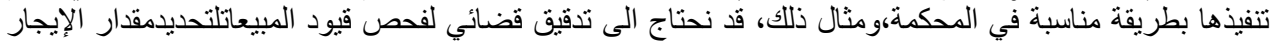

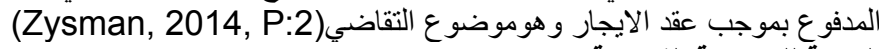
الحاجة للمحاسبة القضائية

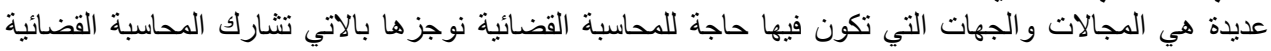

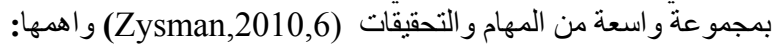

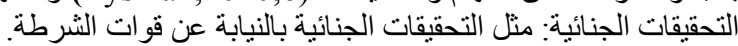

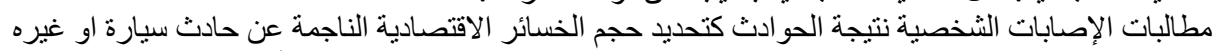

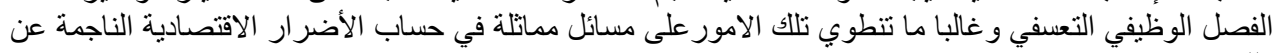

4- مطالباتالموظف: : الامريتطلب التحقيق في قضايا التغطية والأسلوب المناسب لحساب الخسارة.

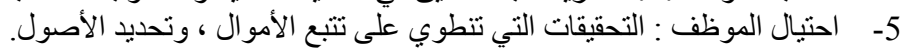

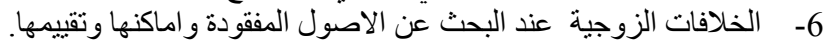

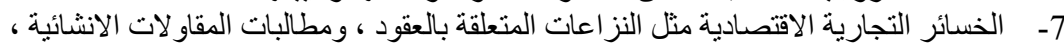

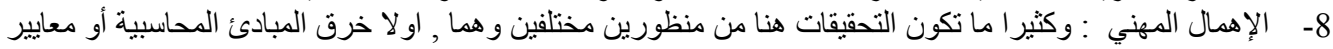

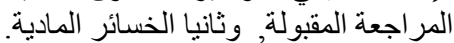

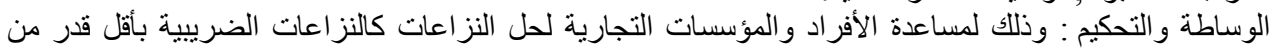

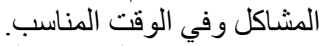
القضاء و المحاسبة القضية القضية المناية دور المحاسبة القضائية في المحكمة هو تطبيقة لإنية لاستخدامات المحاسبة، والتدقيق، ومهار وات التحقق للحضور في

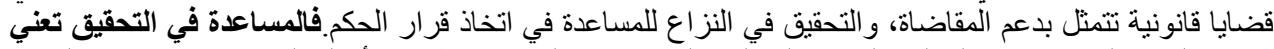

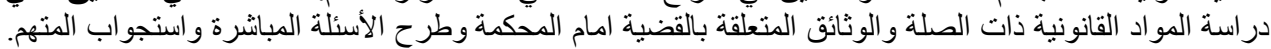

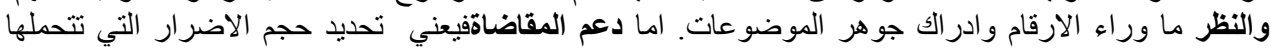

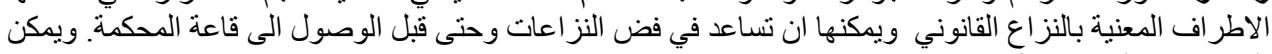
تلخيص هذا الدعم بما يلي (Sanchez and Trewin,2004,p.233 ).

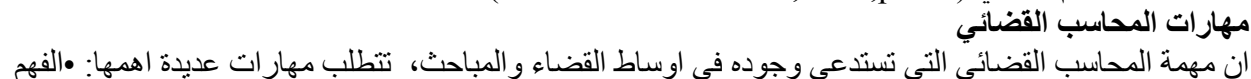

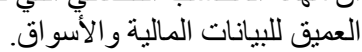

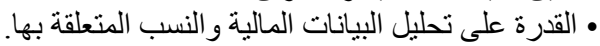

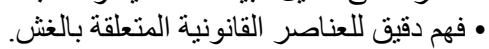

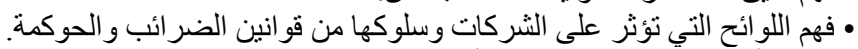

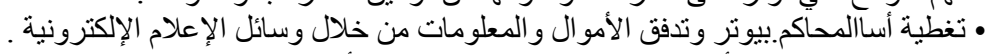

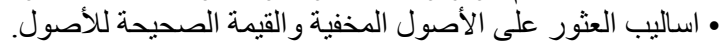

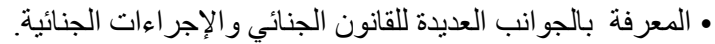

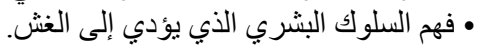

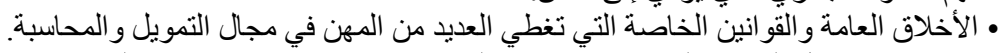

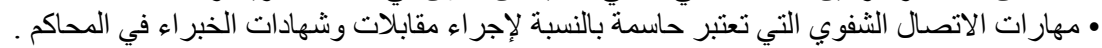

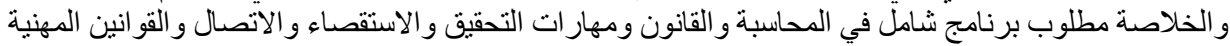

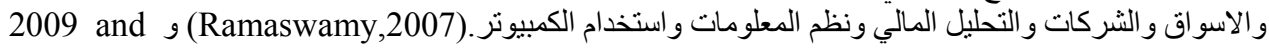
: Asaolu), Owojori(

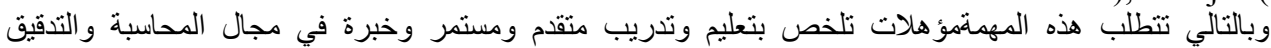

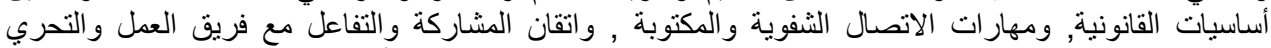

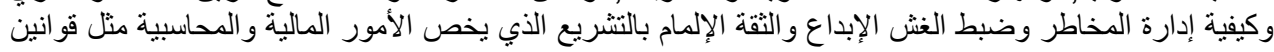


التجارة والشركات ونظام مسك الدفاتر. التأهيل الأكاديمي والمهني والحصول على شهادة خبرة في مجال

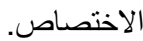

تزايد الحاجة للمحاسبة القضائية

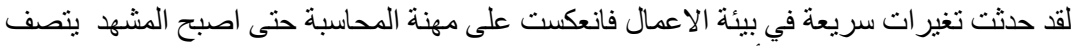

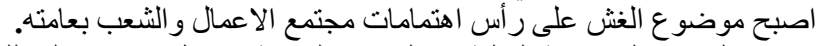

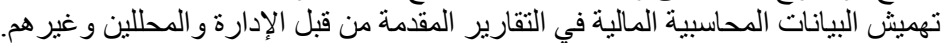

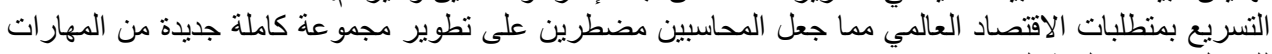
للتعامل مع هذه البيئة المتغيرة .

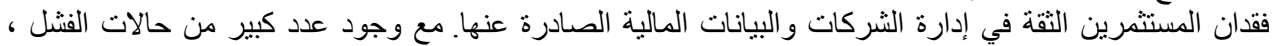

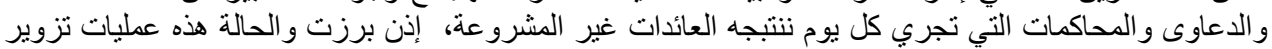

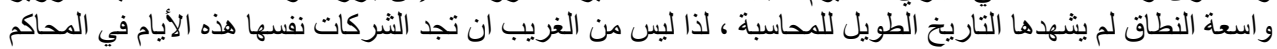

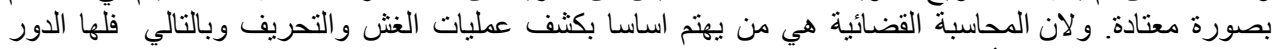

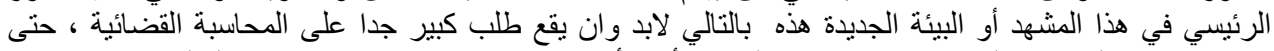

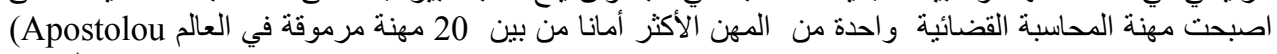

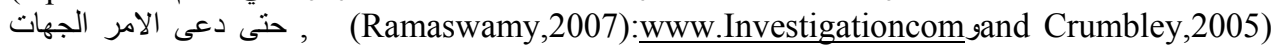
المهنية و الاكاديميةالى وضع شروط خاصة للحصول على رخصة محاسب قضائي.

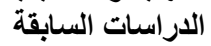
الاراسات باللغة العربية

دراسة قنديل(2014) بعنوان "المهارات المطلوبة من المحاسبين القاتونيين الاردنيين للممارسة المحاسبة

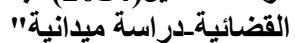

هدفت الدراسة الى التعرف على مدى امتلاك المحاسبين القانونيين الاردنيين للمهارات المطلوبة لممارسة المحاسبة

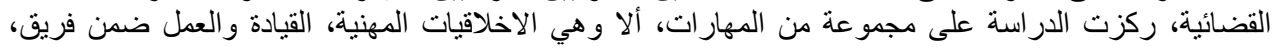

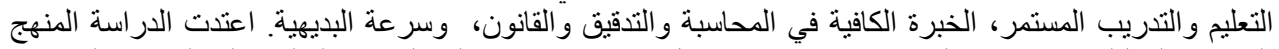

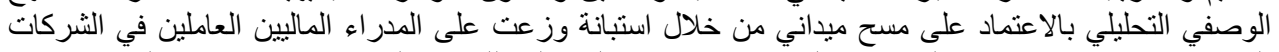

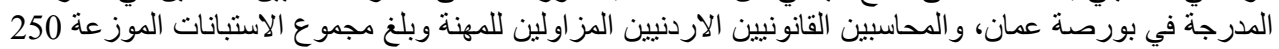

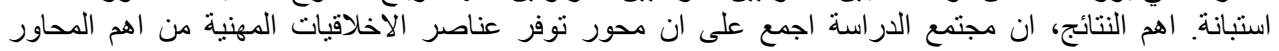

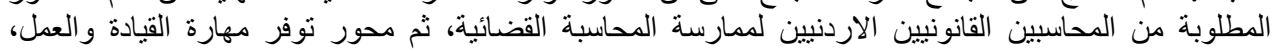

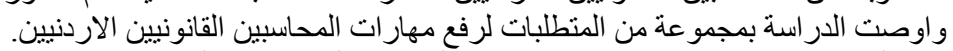

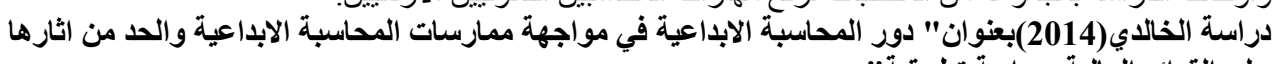

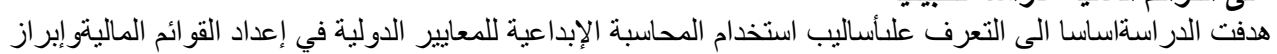

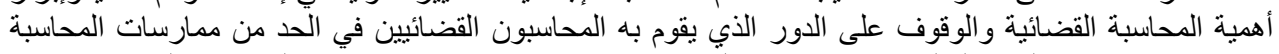

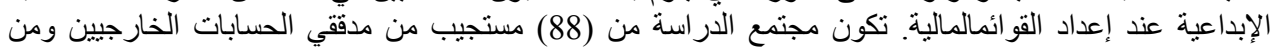

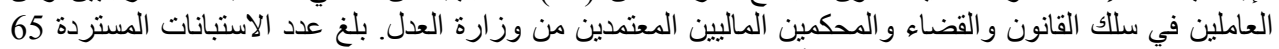

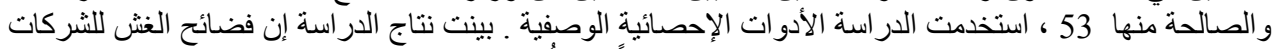

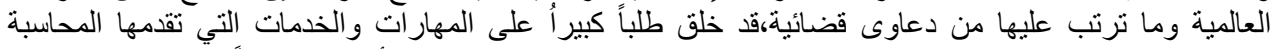

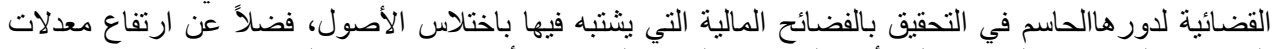

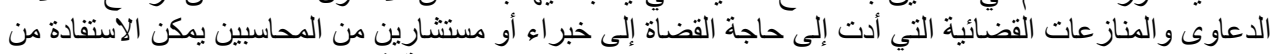

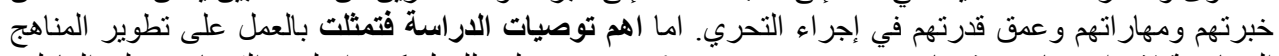

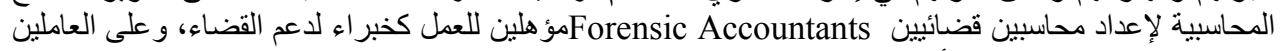

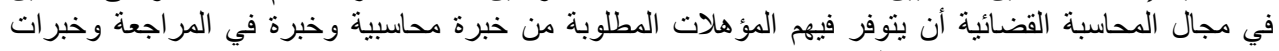

\section{(بعنوان 2003(} قانونية مميزة وخبرات في مجالات الحاسوب.

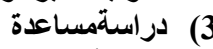

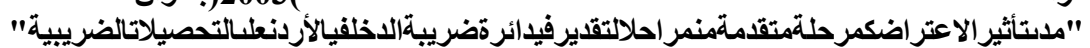

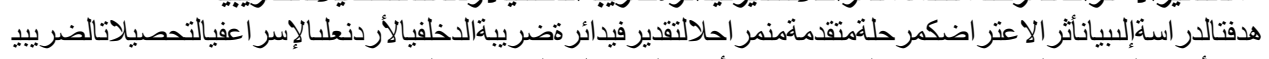

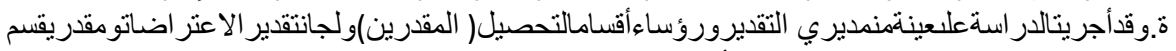

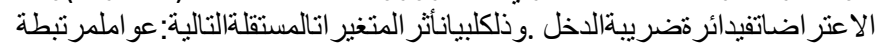

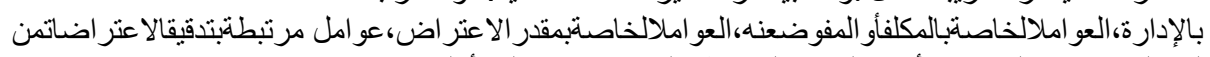

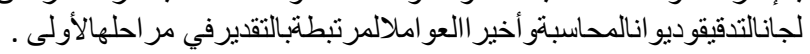




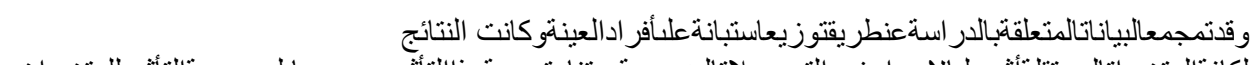

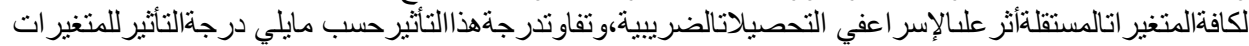

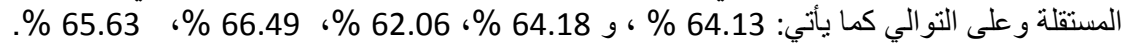

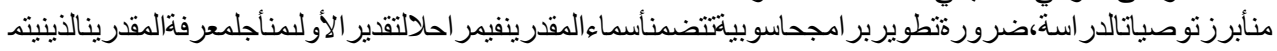

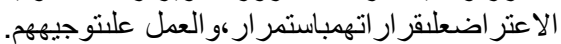

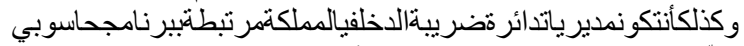

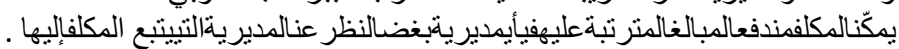

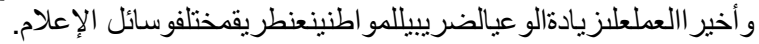
الداسات باللغة الانكليزية:

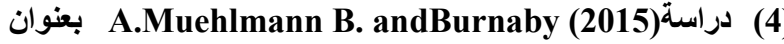
"Masters in Federal Tax Cases the Role of Special as Identified in Court Opinions"

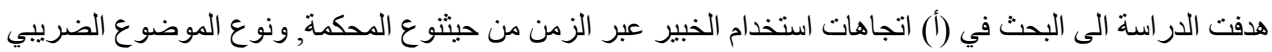

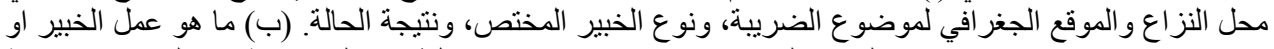

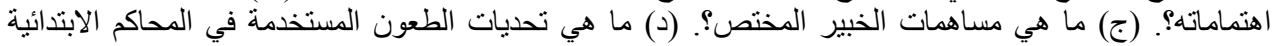

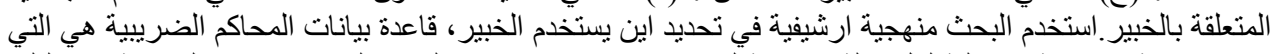

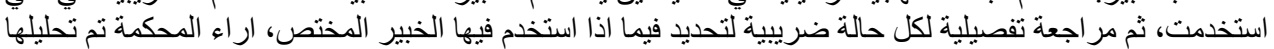

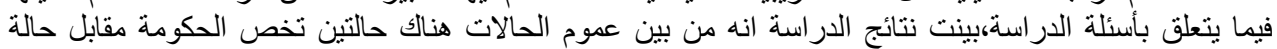

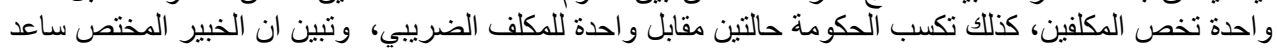

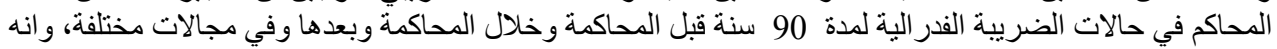

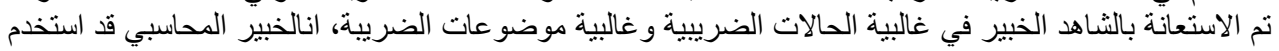

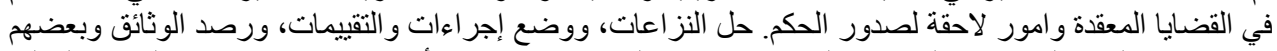

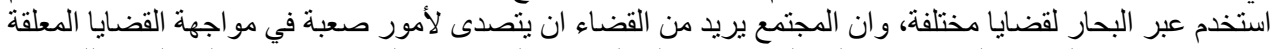

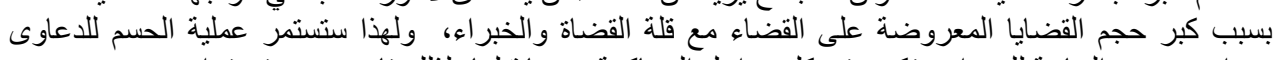

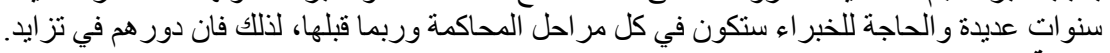

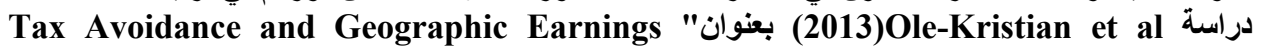

Disclosure"

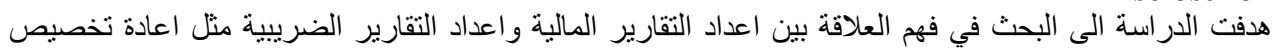

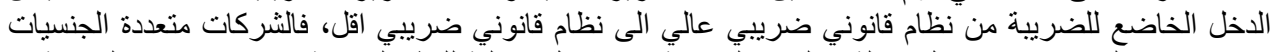

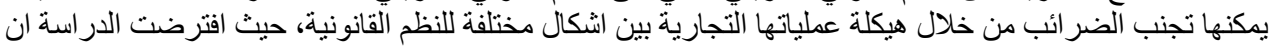

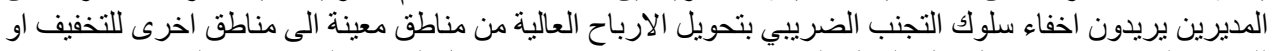

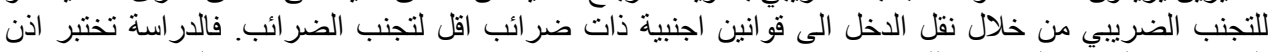

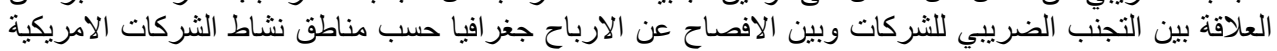

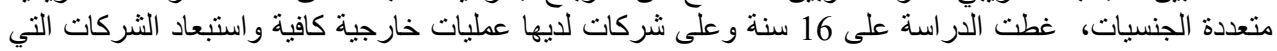

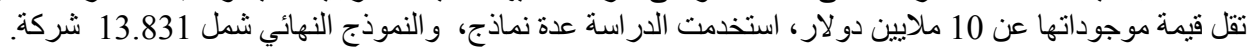

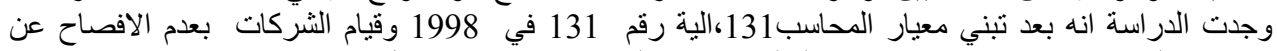

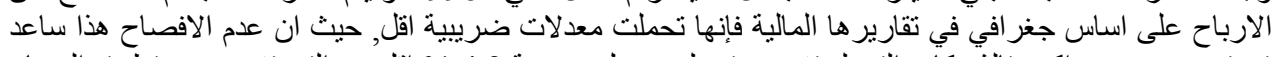

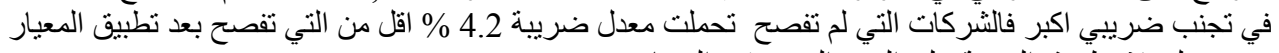

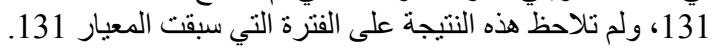
(2012) W. Muehlmann دراسة

The Use of Forensic Accounting Experts in Tax Cases as Identified in Court Opinions

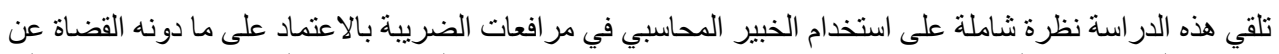

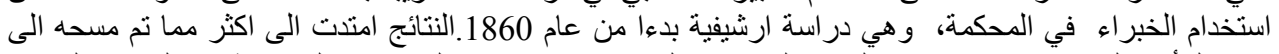

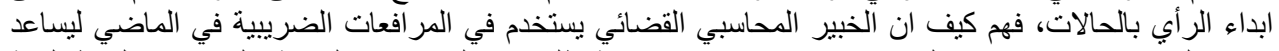
دافعي الضر ائب ومستثاريهم القانونيين في تحديد مدى امكانية طلب هذا الخبير الخير عند الحاجة على أساس النقاط الستة

1- كيف يتم غالبا اعتماد خبير محاسبي قضائي في حالات الضريبة من قبل القضاة عبر الزمن

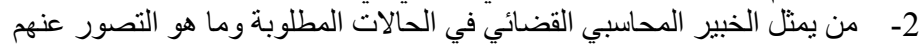




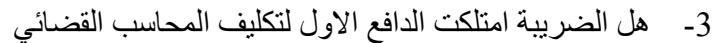

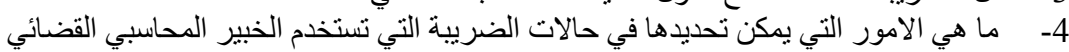

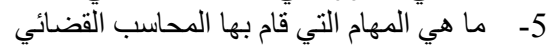

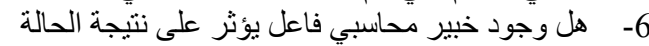

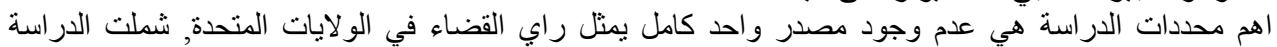

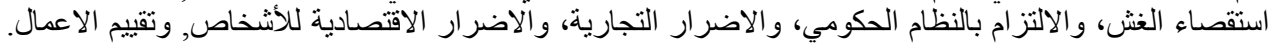

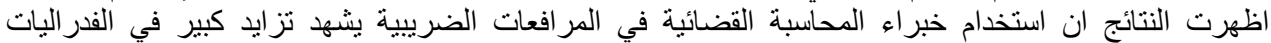

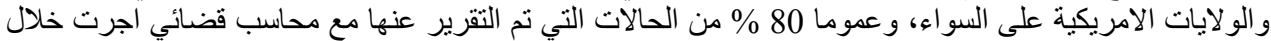

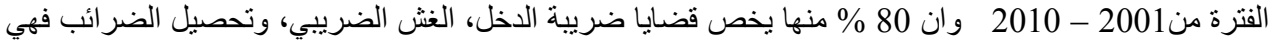

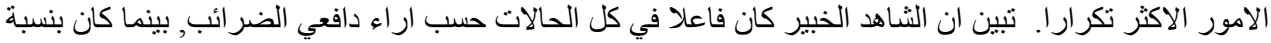
54\% بالنسبة للقضاة. من اهم ما اوصت الدراسة هو البحث في اسباب اختيار المكلفين لثهادة المحاسب القضائي.

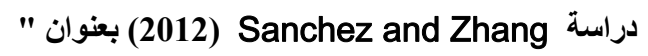

\section{"THE ROLE OF THE EXPERT WITNESS IN ACCOUNTING FRAUD CASES"}

هدفت هذه الدراسة الى بيان دور ومؤهلات الثاهد الخبير مع اعطاء امثلة لأكبر حالتي غش في العالم التي استخدم

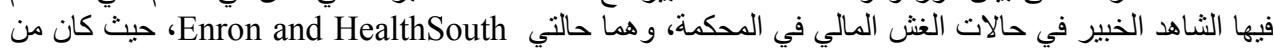

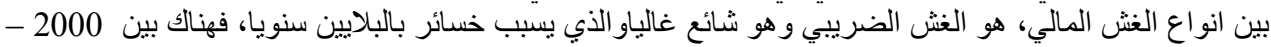

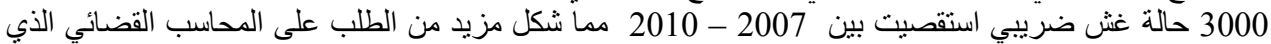

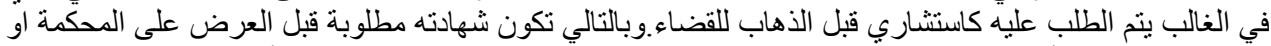

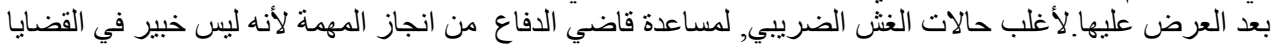

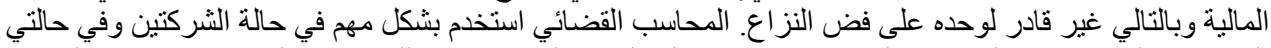

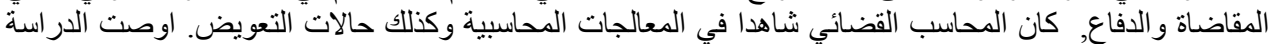

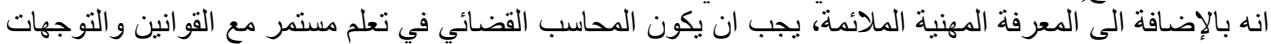

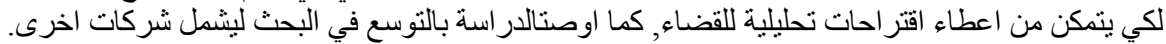

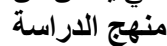

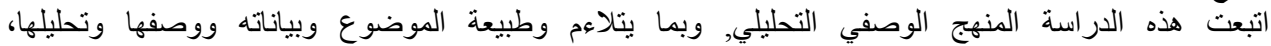

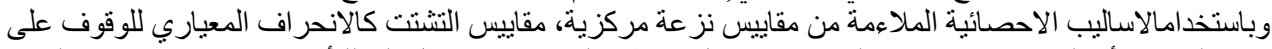

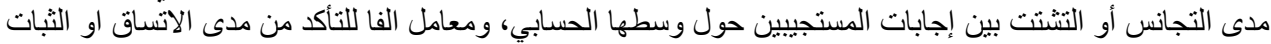

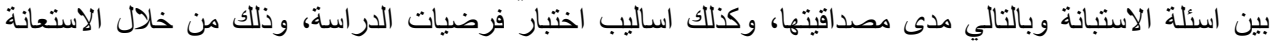
بالرزمة الاحصائية للعلوم الاجتماعية (SPSS). الداة الاراسة الاستة

للجزء الاول من مجتمع الدراسة والمتعلق بالتقديرات، وبسبب عدم توفر بيانات موثقة عن تقديرات دور المحاسبة

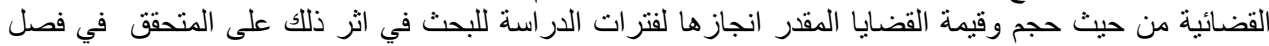

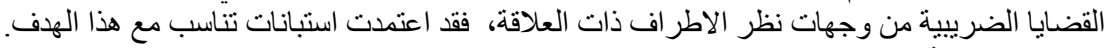

مقياس الاستبانة

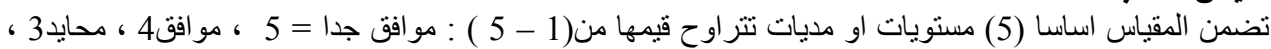

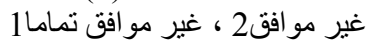

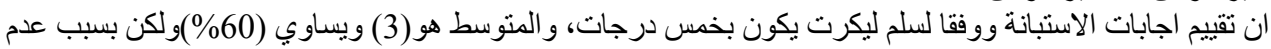

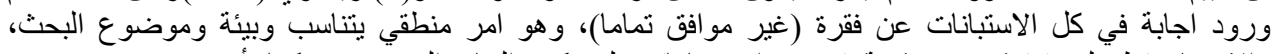

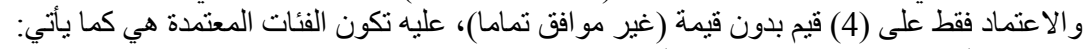

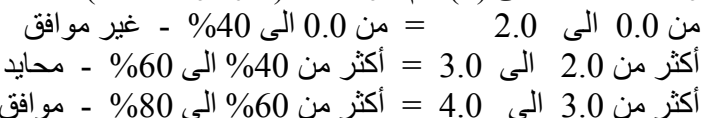

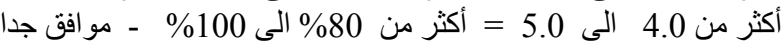

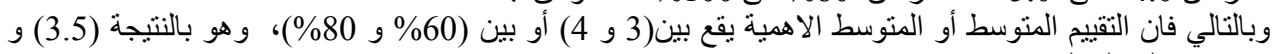

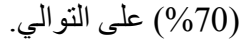




\section{مجتمع وعينة الاراسة}

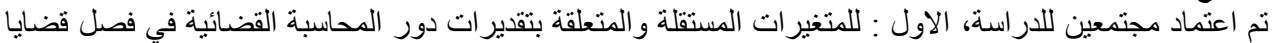

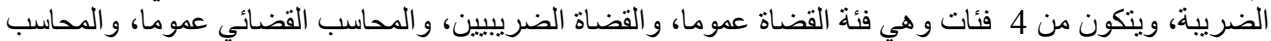

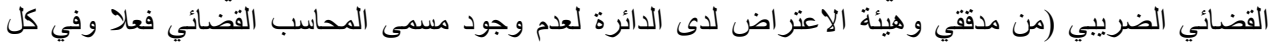

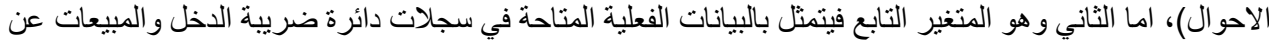

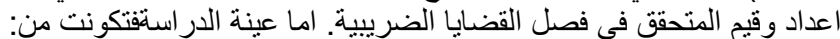

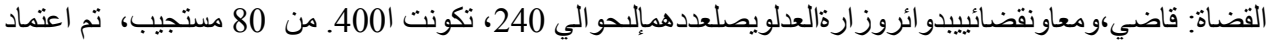
فقط 56 استبانة.

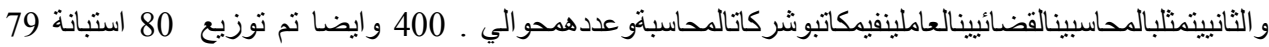
منها صالحة فقط , وبذللك يكون المجموع الكلي 135 استبانة

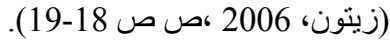

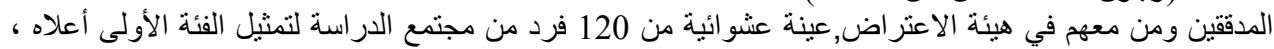

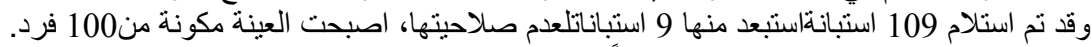

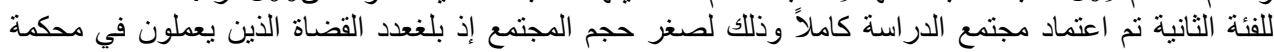
البداية الضرييية 10 قضاة فقط.

تحليل خصائص عينات الدراسة المتغيرات الايموغرافية لأفراد عينة الدراسة

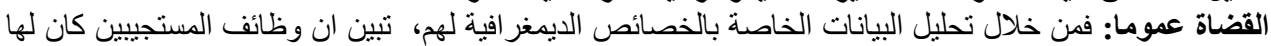

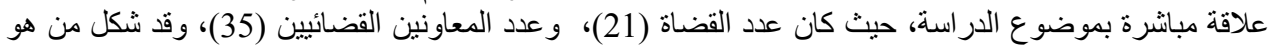

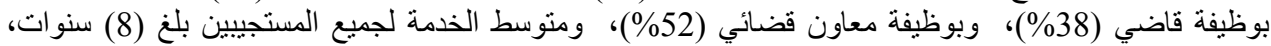

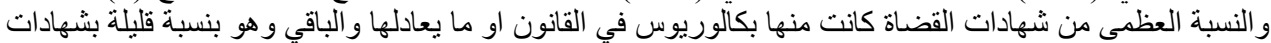

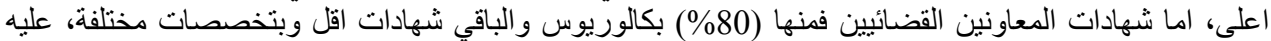

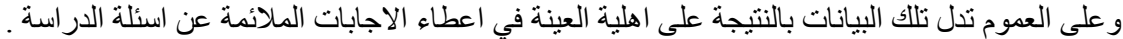

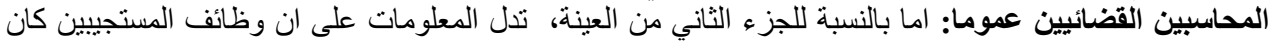

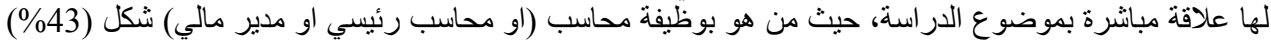

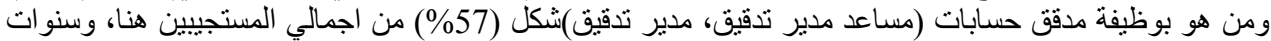

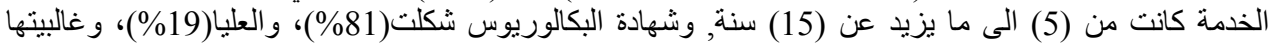

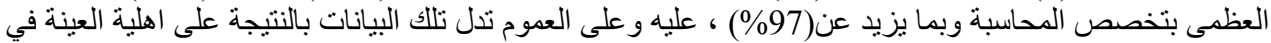

اعطاء الاجابات الملائمة عن اسئلة الدراسة.

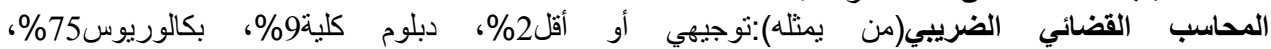

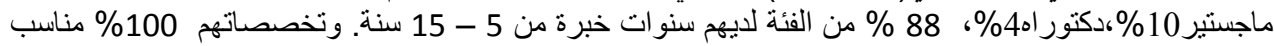

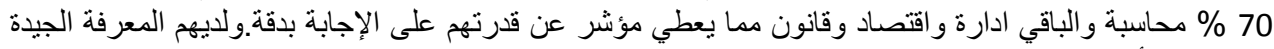

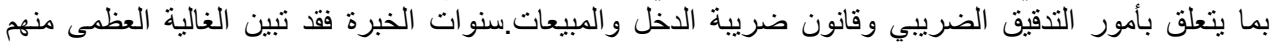

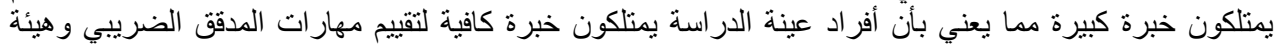

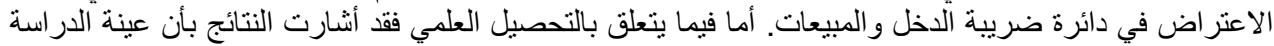
توزعت بين (70\%) يحملون تخصص الحانسبة و وائرة (15\%) تخصص القانون، و (15\%) علوم مالية ومصرفية

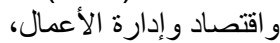

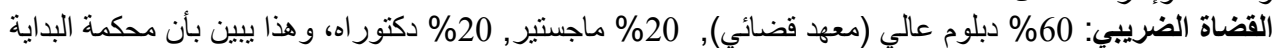

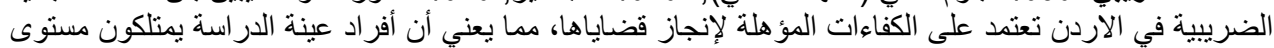

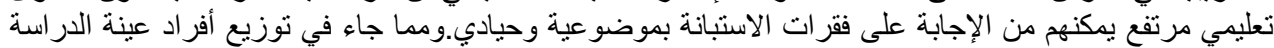

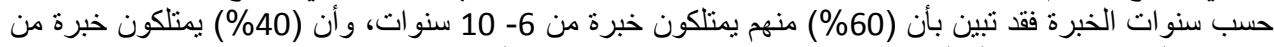

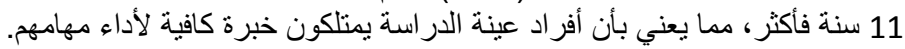
مصادر بيانات الاراسة مئة

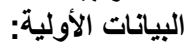

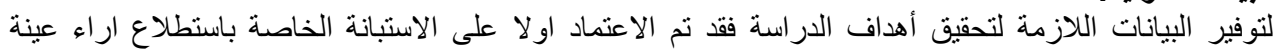

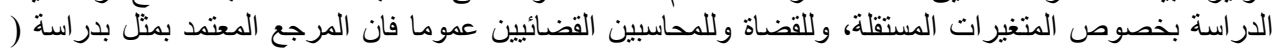

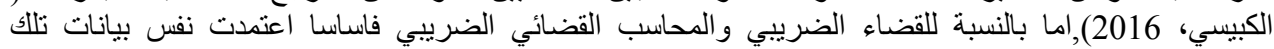

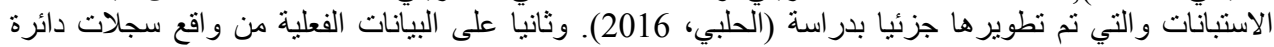

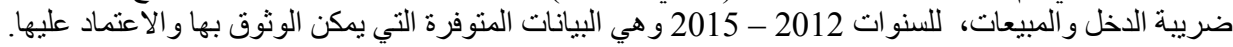




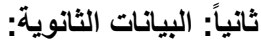

تمثل الكتب و الدوريات والثانوية: الرسائل الجامعية والمجلات العلمية والمقالات والمبات المواقع الحديثة على الثبكة العنكبوتية التي

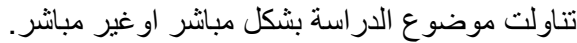

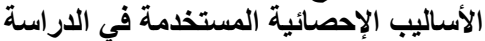

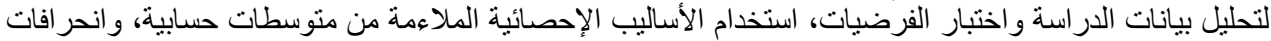

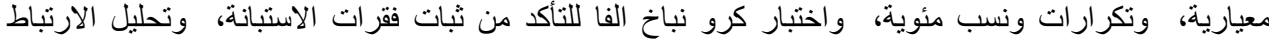

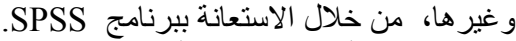
اختبار مصداقية بيانات الاراسة الأنة

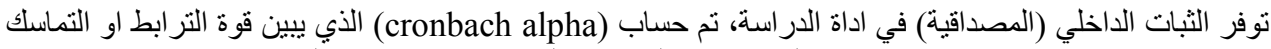

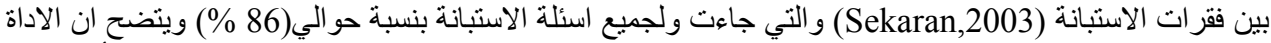
تتصف بقيمة ثبات عالية جدا وذللك لان معامل الثبات المقبول في مثل هذه الدراسة نم تحديده وفقا للفقرة (أ) السابقة الألة

بمقدار Alpha

فرضيات الدراسة:

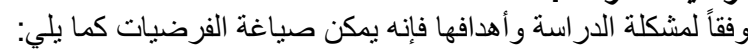

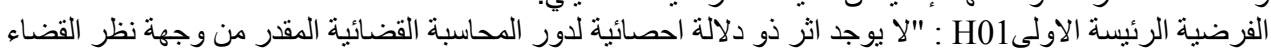

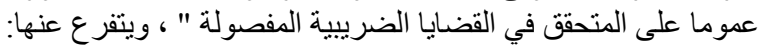

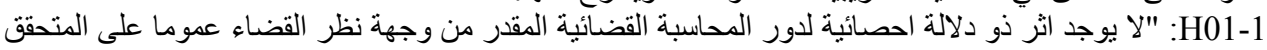

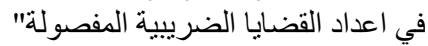
في H01-2 "لا يوجد اثر ذو دلالة احصائية لدور الححاسبة القضائية المقدر من وجهة نظر القضاء عموما على المتحقق

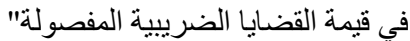
الفرضية الرئيسة الثانية H02 : " لائية يوجد اثر ذو دلالة احصائية لدور المحاسبة القضائية المقدر من وجهة نظر

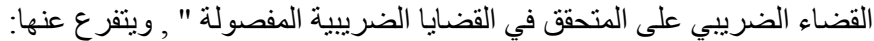

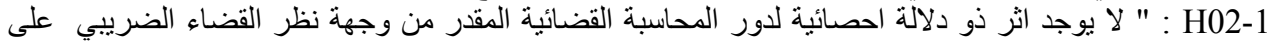

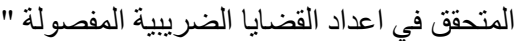

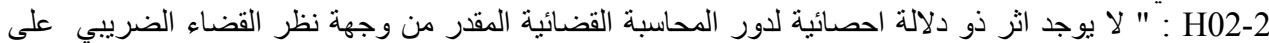

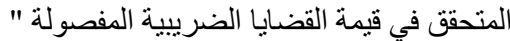

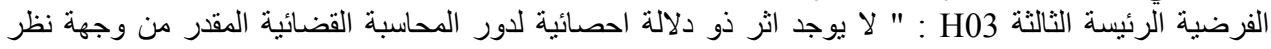

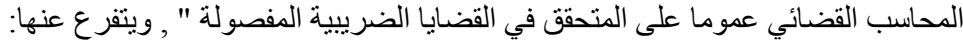

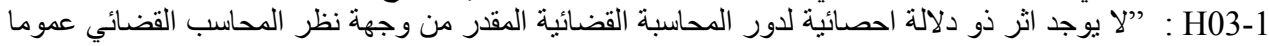

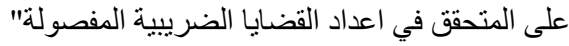
H03-2

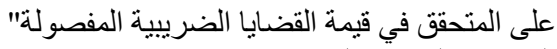

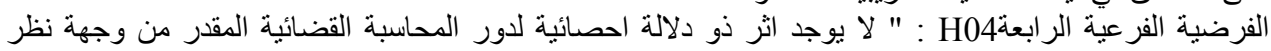

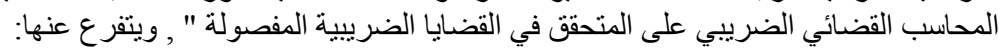

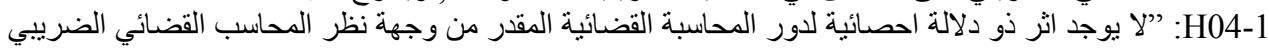

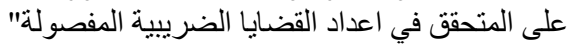

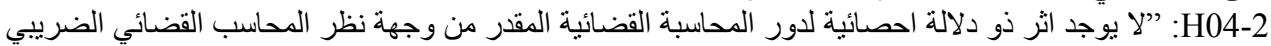

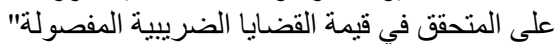

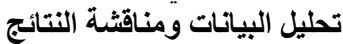

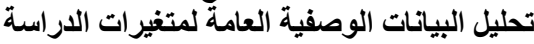
تحليل البيانات الوصفية للمتغيرات التابعة الوصنية

جدول رقم (1) اعداد وقيم (دينار) ملفات القضايا الضريبية للسنوات 2012 - 2015

\begin{tabular}{|c|c|c|c|c|c|c|}
\hline \multicolumn{2}{|c|}{ الملفات المدورة للسنة اللاحقة } & \multicolumn{2}{|c|}{ الملفات المفصولة خلال السنة } & \multicolumn{2}{|c|}{ الملفات الو اردة خلال السنة } & \multirow{2}{*}{ 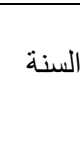 } \\
\hline قيمة & عدد ( عد & قيمة & عدد & قيمة & 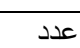 & \\
\hline 118268341 & 900 & 121787574 & 2401 & 299850641 & 2317 & 2012 \\
\hline 397612308 & 2028 & 87064652 & 1577 & 366408619 & 2705 & 2013 \\
\hline 464429982 & 2064 & 210945687 & 2504 & 277763361 & 2540 & 2014 \\
\hline 401769146 & 3108 & 265830094 & 2713 & 203169258 & 3757 & 2015 \\
\hline
\end{tabular}


جدول رق(4) سنواتوى الانجاز على اساس عدد ملفات القضايا الضريبية

\begin{tabular}{|c|c|c|c|}
\hline \% المنجز(ملف) & العدد الكلي للسنة & عدد المنجز & السنة \\
\hline 0.73 & 3301 & 2401 & 2012 \\
\hline 0.44 & 3605 & 1577 & 2013 \\
\hline 0.55 & 4568 & 2504 & 2014 \\
\hline 0.47 & 5821 & 2713 & 2015 ش \\
\hline 0.63 & 4324 & 2717 & المعدل (4) سنوات \\
\hline
\end{tabular}

جدول (3) مستوى الانجاز على اساس قيمة القضايا الضريبية (دينار)

\begin{tabular}{|c|c|c|c|}
\hline \% المنجز & الضر ائب الكلية المفروضة للسنة & قيمة المنجز(المفصول) & السنة \\
\hline$\% 41$ & 299850641 & 121787574 & 2012 \\
\hline$\% 18$ & 484676960 & 87064652 & 2013 \\
\hline$\% 31$ & 675375669 & 210945687 & 2014 \\
\hline$\% 40$ & 667599240 & 265830094 & 2015 \\
\hline $\begin{array}{r}\text { \% } 32 \\
\text { المتوسط }\end{array}$ & 2127502510 & 685628007 & المجموع \\
\hline
\end{tabular}

جدول ( 4 ) التحليل الوصفي لمتغيرات الاراسة المستقلة

\begin{tabular}{|c|c|c|c|c|c|}
\hline الالمعياري & الحستوسطي & قيمة & قيمة & $\mathbf{N}$ & المتغير \\
\hline .157 & 4.01 & 4.29 & 3.86 & 7 & المقدر حسب وجهة نظر القضاء عموما \\
\hline .589 & 4.13 & 4.80 & 2.70 & 10 & المقدر حسب وجهة نظر القضناء الضريبي \\
\hline .149 & 4.06 & 4.28 & 3.90 & 7 & المقدر حسب وجهة نظر المحاسب القضائي عموما \\
\hline .135 & 3.87 & 4.11 & 3.59 & 20 & المقدر حسب وجهة نظر المحاسب القضائي الضريبي \\
\hline .130 & .548 & 0.73 & 0.44 & 4 & فصل قضايا ضريبية مستوى الانجاز على اساس عدد الملفات \\
\hline .107 & .325 & 0.41 & 0.18 & 4 & فصل قضايا ضريبية مستوى الانجاز على اساس قيم الملفات \\
\hline
\end{tabular}

ان المعدل العام للمتوسط الحسابي للمقدر حسب وجهات النظر المختلفة للمستجيبين بلغ اكبر من 4 حيث يبين أن جميع المباء

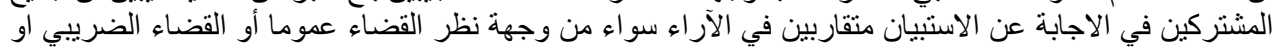

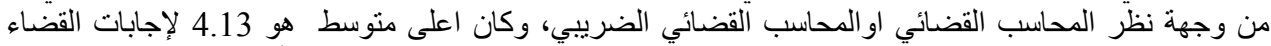

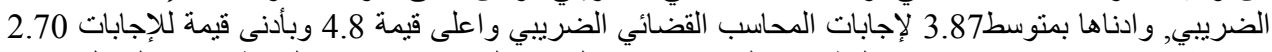

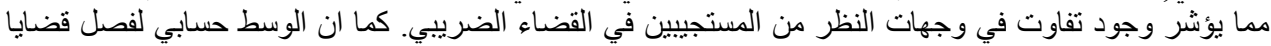

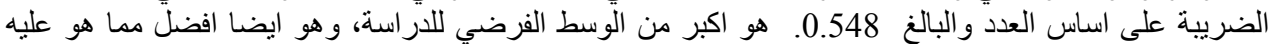

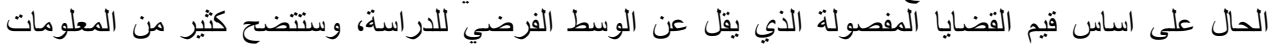

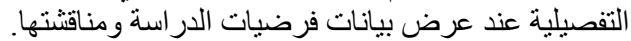
عرض وتحليل بيانات الفرضية الرئيسة الاولي ومناقشة نتائجها

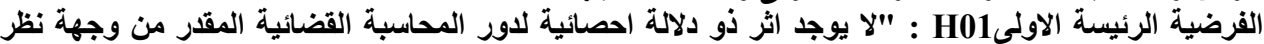

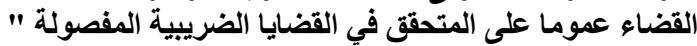

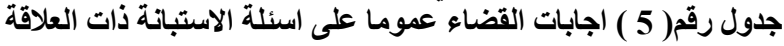


Estimations Effect of the Forensic Accounting

\begin{tabular}{|c|c|c|c|}
\hline 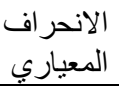 & 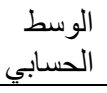 & الســـؤال & ت \\
\hline 0.84 & 4.14 & تلأداء المهيمة في الاستشاري المالي ( الثاهد الخبير ) المؤهلات العالية المطلوبة & 1 \\
\hline 0.81 & 4.00 & 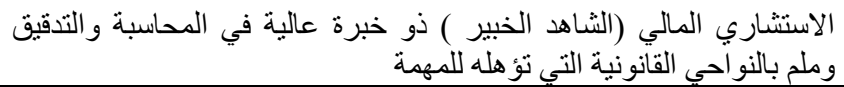 & 2 \\
\hline 0.88 & 3.86 & 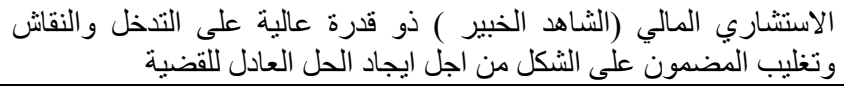 & 3 \\
\hline 0.76 & 3.93 & 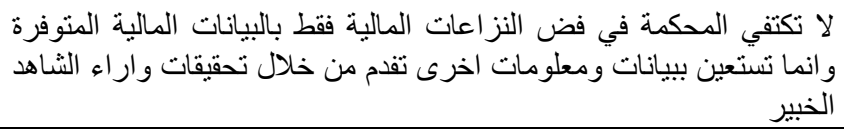 & 4 \\
\hline 0.81 & 4.00 & 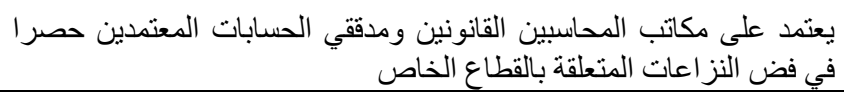 & 5 \\
\hline 1.00 & 4.29 & الحكومي على ديوان المحاسبة حصرا في فض النزاعات المتعلقة بالقطاع & 6 \\
\hline 0.96 & 3.86 & النزواعات خبير مالية معين لدى المحكمة يعتمد لا بداء المشورة في فض & 7 \\
\hline 0.87 & 4.01 & المنوسط العام & \\
\hline
\end{tabular}

و اهم ما يتضح من تحليل البيانات اعلاه:

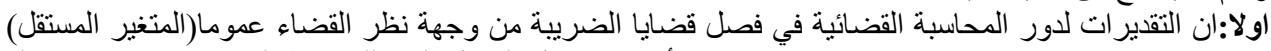

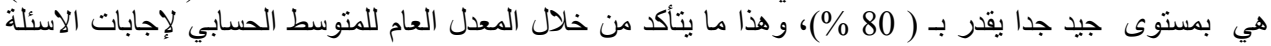

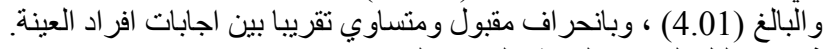
ثُانيا: تحليل البيانات الكمية (المتغير التابع) يبين:

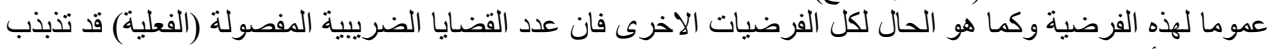

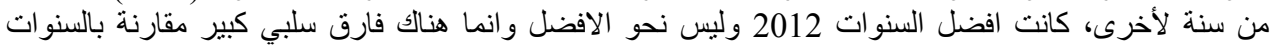

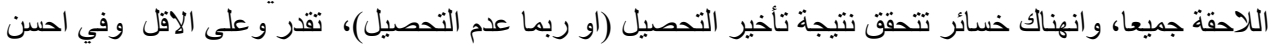

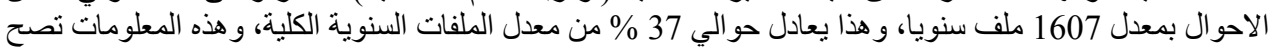
لكل فرضيات الدراسة. تحليل البيانات على اساس كل فرضية:

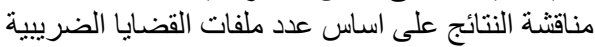
.2 لم يصل المنجز الفعلي من الملفات التي تم فصل قضاياها ولأي سنة من سنوات الدراسة الى مقدار التقديرات المعطاة

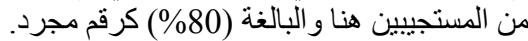

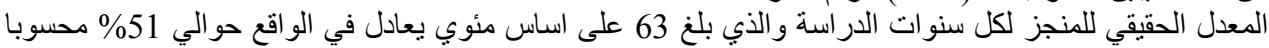

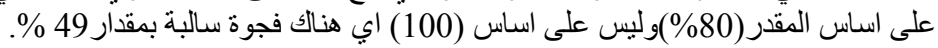

(ب) مناقثة النتائجعلى اساس قيج(دينار ) القضايا الضريبية

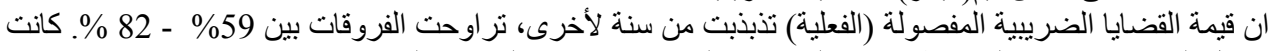

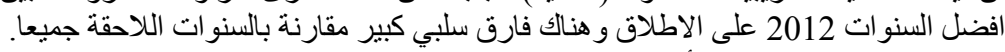

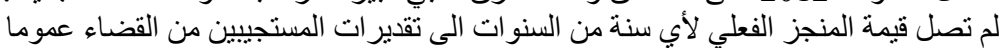

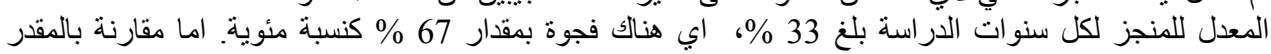
(80)

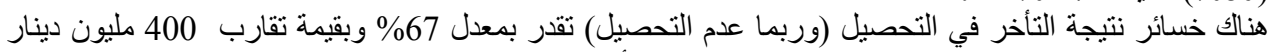

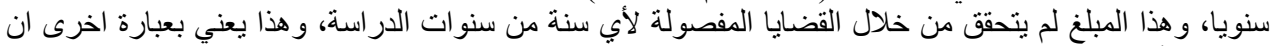

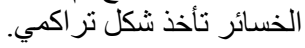


ولتقييم اثر هذه النتائج القديرات (المتغيرات المستقلة)على المتحقق فعلا في فصل القضايا الضريبية (المتغيرات

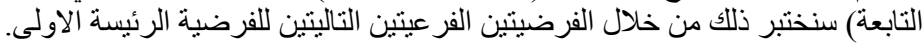

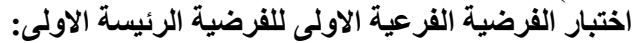

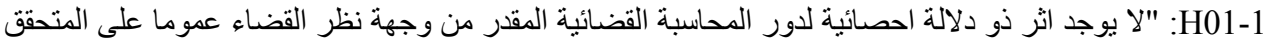

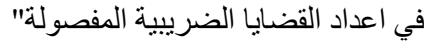
جدول (6 ) العلاقة بين المقدر والمتحقق في اعداد القضايا المفصولة من وجهة نظر القضاء عموما

\begin{tabular}{|c|c|c|c|c|c|}
\hline $\mathbf{R}$ & R2 & Adj R & F & Sig & \\
\hline $.656^{\mathrm{a}}$ & .430 & .145 & 1.508 & .344 & وجهة نظر القضاء عموماً المضائية من \\
\hline & & $T$ & Beta & Sig & \\
\hline & & 1.228 & .700 & .344 & \\
\hline
\end{tabular}

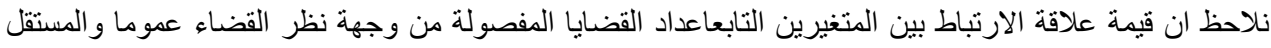

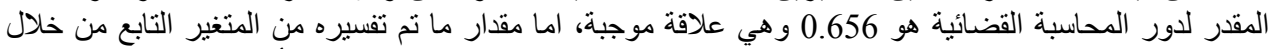

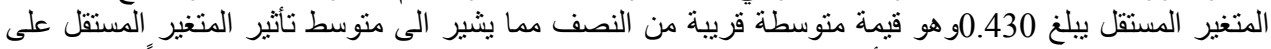

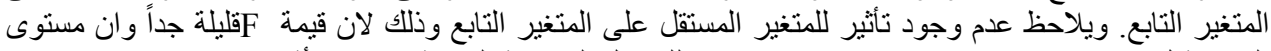

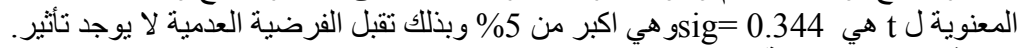

\section{$\mathrm{Y} 1=-2.24+0.700 \mathrm{X} 1$}

النموذج الخطي لمعادلة الانحدار البسيط

* معادلة خط الانحدار التي تمثل العلاقة بين المتغير المستقل X و المتغير التنابع Y فكلما زادت Y واحد تزيد

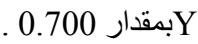

اختبار الفرضية الفرعية الثانية للفرضية الرئيسة الاولى: H01-2 "لائيا يوجد اثر ذو دلالة احصائية لدور المحاسبة القضائية المقدر من وجهة نظر القضاء عموما على المتحقق في قيمة القضايا الضريبية المفصولة دلانة جذول (7 ) العلاقة بين المقدر والمتحقق في قيمة القضايا المفصولة من وجهة نظر القضاء عموماً

\begin{tabular}{|c|c|c|c|c|c|}
\hline $\mathbf{R}$ & R2 & Adj R & $\mathbf{F}$ & Sig & \\
\hline .229 & .052 & -.422 & .110 & .771 & لمن وجهة لدور القضاءبة القضائية عموماً \\
\hline & & $\mathbf{T}$ & Beta & Sig & \\
\hline & & .332 & .200 & .771 & \\
\hline
\end{tabular}

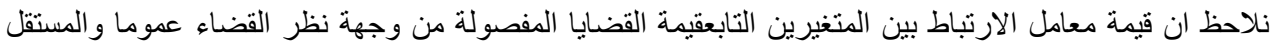

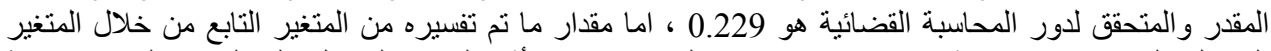

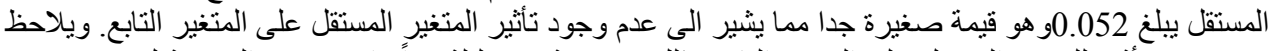

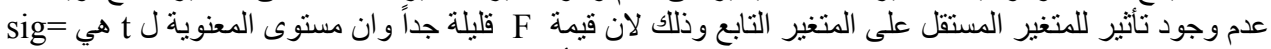

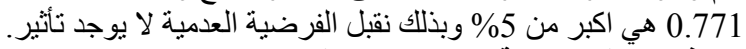
النموذج الخطي لمعادلة الانحدار البسيط $Y 2=-.471+.200 \times 2$

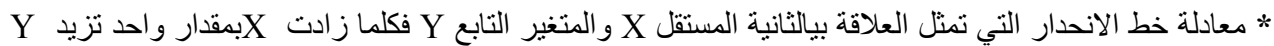

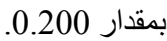
عرض وتحليل بيانات الفرضية الرئيسة الثانية ومناقشة نتائجها:

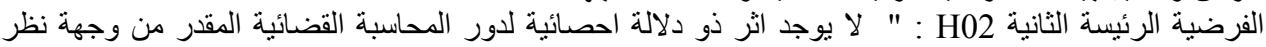

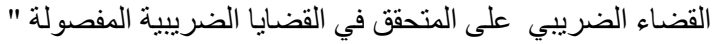


Estimations Effect of the Forensic Accounting

جدول رقم ( 8) عرض بيانات الفرضية الرئيسة الثانية

\begin{tabular}{|c|c|c|c|}
\hline 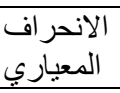 & 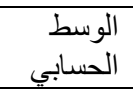 & السؤال & ت \\
\hline 0.70 & 4.60 & على محكمة البداية الضريبية المالية تشكل العدد الاكبر من بين القضايا التي تعرض & 1 \\
\hline 0.63 & 4.80 & 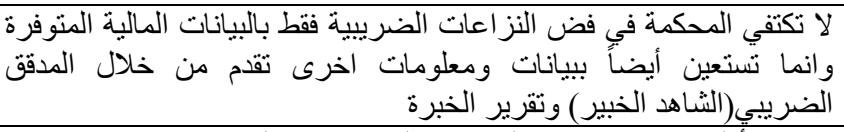 & 2 \\
\hline 0.47 & 4.00 & تتوفر الأَدلة وبما يؤمن فض النزاعات الضرييية بعدالة & 3 \\
\hline 0.42 & 4.20 & تتوفر الأدلة بالتفاصيل المطلوبة وبما يؤمن فض النز اعات الضرييية & 4 \\
\hline 0.57 & 3.90 & النزوفات في تقريبر الخبرة المحاسبية التفاصيل المطلوبة وبما يؤمن فض & 5 \\
\hline 0.48 & 4.70 & الضوفيية تقرير الخبرة المحاسبية بالكلفة الملائمة وبما يؤمن فض النزاعات & 6 \\
\hline 0.95 & 2.70 & الضوفيبية فتريز الخبرة المحاسبية في الوقت المناسب وبما يؤمن فض النزاعات & 7 \\
\hline 0.42 & 4.20 & يتم اعتماد تقرير الخبرة المحاسبية بالكامل كدليل في فض النزاعات الضرييية & 8 \\
\hline 0.32 & 4.10 & الضُريية اعتماد جزءٌ من تقرير الخبرة المحاسبية كدليل في فض النزاعات & 9 \\
\hline 0.32 & 4.10 & يعتبر الددقق الضريبي (الثاهد) من أدلة الإثبات في فض النزاعات الضريبية & 10 \\
\hline 0.19 & 4.13 & المتوسط العام & \\
\hline
\end{tabular}

و اهم ما يتضح من تحليل البيانات اعلاه:

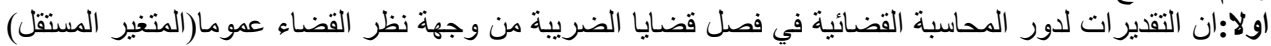

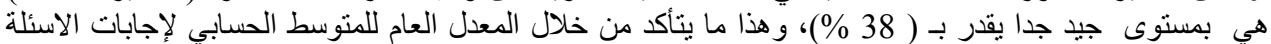

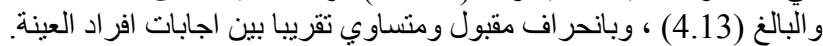

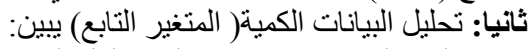

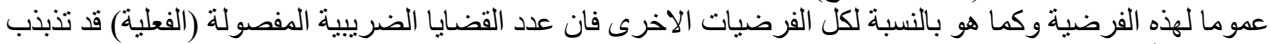

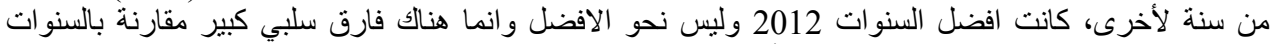

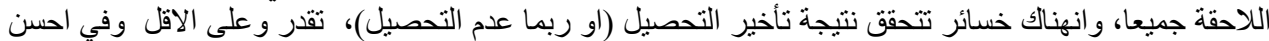
الاحو ال بمعدل 1607 ملف سنويا، و هذا يعادل حوالي 37 \% م من معدل الملفات السنوية الكلية، و هذه المعلومات الئات تصح لكل فرضيات الدراسة. تحليل البيانات على اساس كل فرضية النية

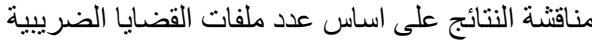

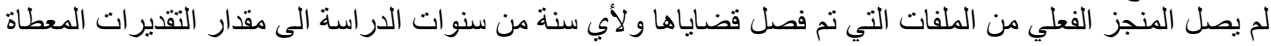

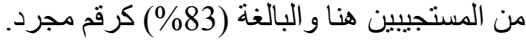

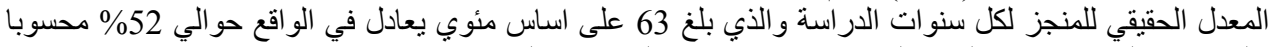

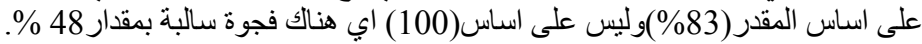

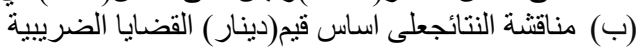

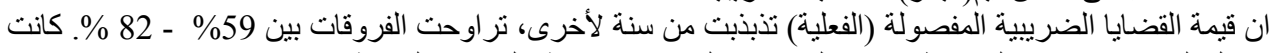

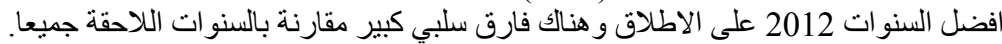

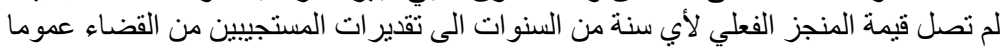

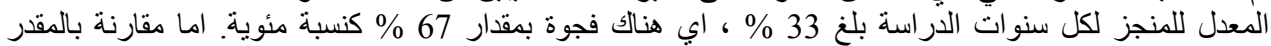

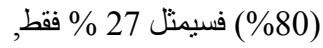


هناك خسائر نتيجة التأخر في التحصيل (وربما عدم التحصيل) تقدر بمعدل 67\% وبقائ لإيمة تقارب 400 مليون دينار

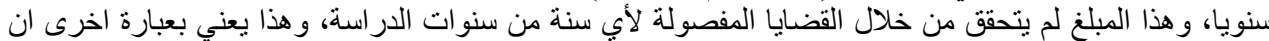

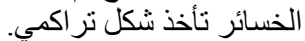
ولتقييم اثر هذه النتائج التقديرات (المتغيرات المستقلة)على المتحقق فعلا في فصل القضايا الضريبية (المتغيرات

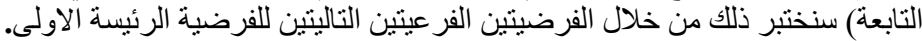
اختبار الفرضية الفرعية الاولى للفرضية الرئيسة الثرانية الثرانية:

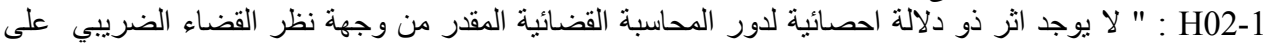

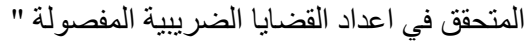
جلول (9) العلاقة بين المقدر والمتحقى في اعداد القضايا المفصولة من وجهة نظر القضاء الضريبي

\begin{tabular}{|c|c|c|c|c|c|}
\hline $\mathbf{R}$ & $\mathbf{R 2}$ & Adj R & F & Sig & \\
\hline \multirow[t]{3}{*}{.056} & .003 & -.495 & .006 & .944 & من وجهة نظر القضاء الضريبية القيائي \\
\hline & & $\mathbf{T}$ & Beta & Sig & \\
\hline & & .079 & .020 & .944 & Constant) \\
\hline
\end{tabular}

نلاحظ ان قيمة معامل الارتباط بين المتغيرين التنابعاعداد القضايا المفصولة من وجهة نظر القضاء الضريبي و المستقل

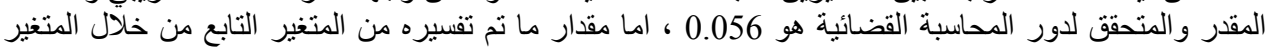

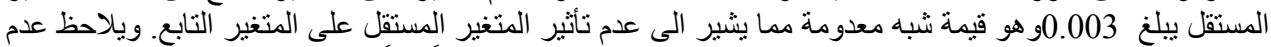

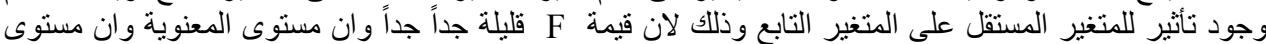

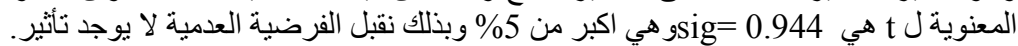

النموذج الخطي لمعادلة الانحدار البسيط

$\mathrm{Y} 1=.460+.020 \times 1$

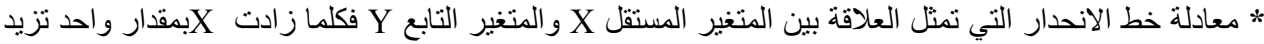

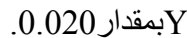

اختبار الفرضية الفرعية الثانية للفرضية الرئيسة الثانية: الم02-2 : " لا يوجد اثر ذو دلالة احصائية لدور المحاسبة القضائية المقدر من وجهة نظر القضاء الضريبي على الفئي

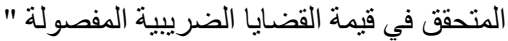

جدول( 10 ) العلاقة بين المقلر والمتحقق في قيمة القضايا المفصولة من وجهة نظر القضاء الضريبي

\begin{tabular}{|c|c|c|c|c|c|}
\hline $\mathbf{R}$ & R2 & Adj R & $\mathbf{F}$ & Sig & \\
\hline .428 & .183 & -.225 & .449 & .572 & والمقدة لظر القضاء الضراسبة القضائية من \\
\hline & & $\mathbf{T}$ & Beta & Sig & \\
\hline & & 6.595 & -.670 & .572 & Constant) \\
\hline
\end{tabular}

نلاحظ ان قيمة معامل الارتباط بين المتغيرين التابعقيمة القضايا المفصولة من وجهة نظر القضاء الضرئ مئي و المستقل

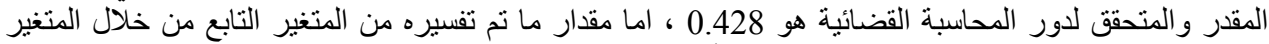

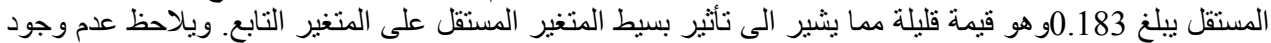

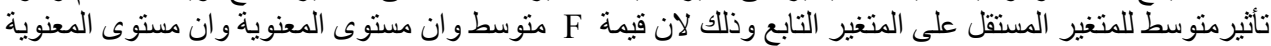

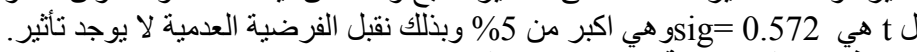
النموذج الخطي لمعادلة الاتحدار البسيط

$$
Y 2=.875+-.125 \times 2
$$

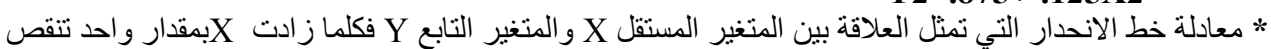

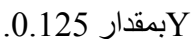
عرض وتحليل بيانات الفرضية الرئيسة الثالثة ومناقشة نتائجها: 
Estimations Effect of the Forensic Accounting

الفرضية الرئيسة الثالثة H03 : " لا يوجد اثر ذو دلالة احصائية لدور المحاسبة القضائية المقدر من وجهة نظر

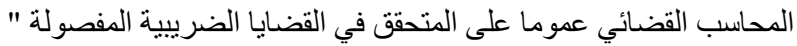

جدول رقم( 11 ): عرض بيانات الفرضية الرئيسة الثالثة

\begin{tabular}{|c|c|c|c|}
\hline 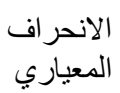 & الحسابي & 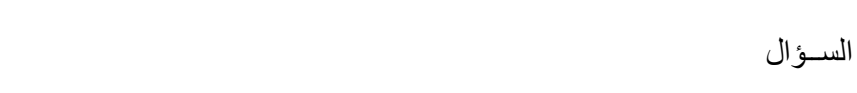 & ت \\
\hline 0.86 & 4.28 & المهيمة في الاستشاري المالي ( الثـاهد الخبير ) المؤهلات العالية المطلوبة لأداء & 1 \\
\hline 0.82 & 4.25 & 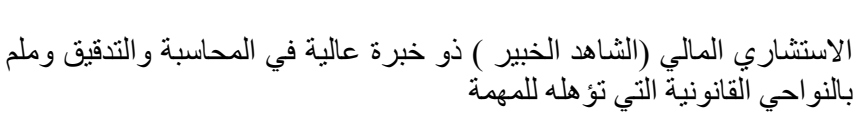 & 2 \\
\hline 0.78 & 3.90 & 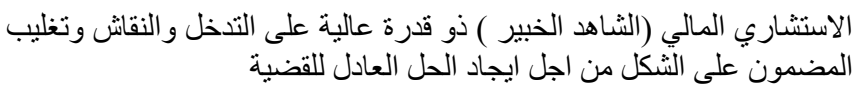 & 3 \\
\hline 0.77 & 4.03 & 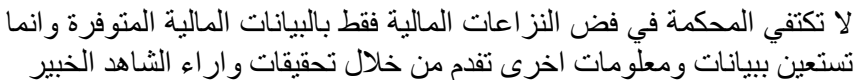 & 4 \\
\hline 0.81 & 4.01 & فضتمد النزاعلى مكاتب المتعة بالسبين القانونين ومدققي الحسابات المعتمدين حصر ا في & 5 \\
\hline 0.85 & 3.97 & يعتمد على ديوان المحاسبة حصر ا في فض النزاعات المتعلقة بالقطاع الحكومي & 6 \\
\hline 0.85 & 3.95 & المالية خبير مالي معين لاى المحكمة يعتمد لا بداء المشورة في فض النزاعات & 7 \\
\hline 0.71 & 4.06 & المتوسط العام & \\
\hline
\end{tabular}

و اهم ما يتضح من تحليل البيانات اعلاه:

اولا:ان التقديرات لدور المحاسبة القضائية في فصل قضايا الضريبة من وجهة نظر القضاء الفياء عموما(المتغير المستقل)

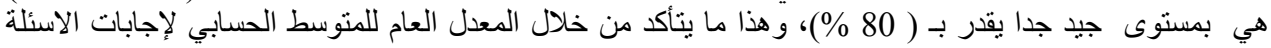

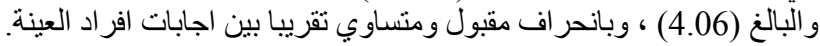

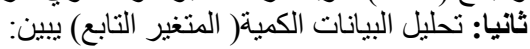

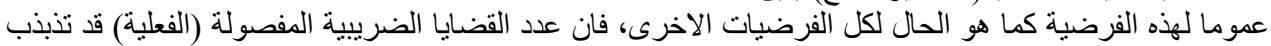

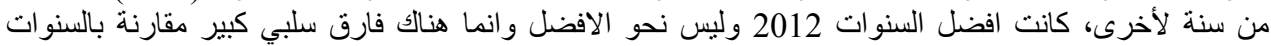

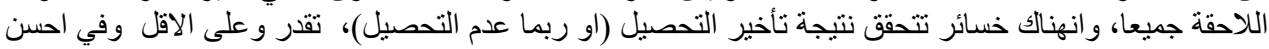

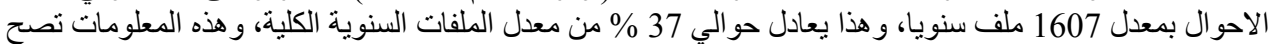
لكل فرضيات الدراسة. 2. 2. تحليل البيانات على اساس كل فرضية:

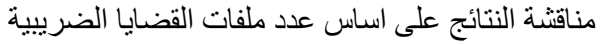

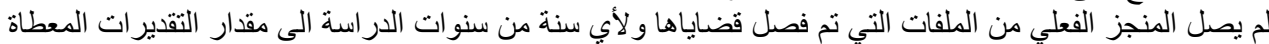

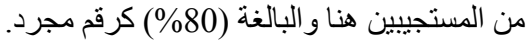

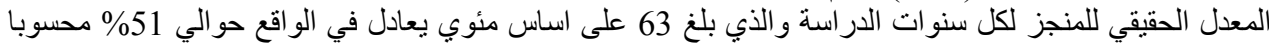

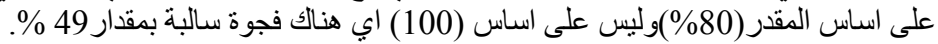

(ب) مناقثة النتائجعلى اساس قيم(دينار ) القضايا الضريبية

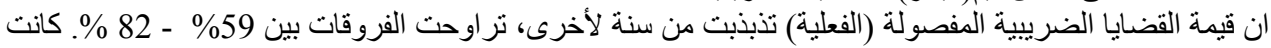
افضل السنوات 2012 على الاطلاق و هناك فارق سلبي كبير مقارنة بالسنوات الترات اللاحقة جميعا. 
لم تصل قيمة المنجز الفعلي لأي سنة من السنوات الى تقدير ات المستجييين من القضاء عموما

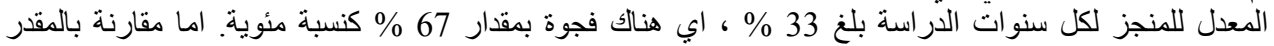

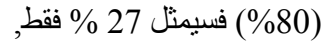

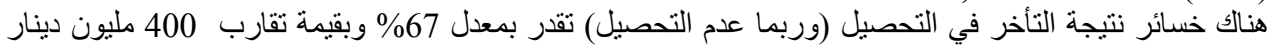

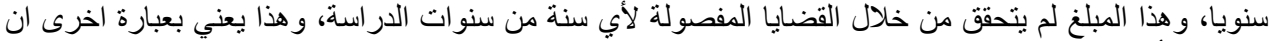
الخسائر تأخذ شكل تر اكمي. ولتقييم اثر هذه النتائج التقديرات (المتغيرات المستقلة)على المتحقق فعلا في فصل القضايا الضريبية (المتغيرات

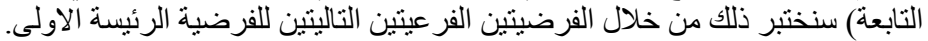
اختبار الفرضية الفرعية الاولى للفرضية الرئيسة الثالثئة:

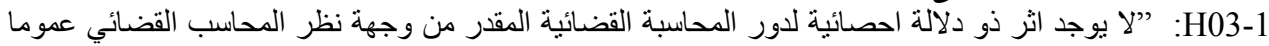

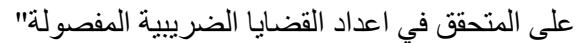
جدول (12) العلاقة بين المقدر والمتحقى في اعداد القضايا المفصولة من وجهة نظر المحاسب القضائي عموماً

\begin{tabular}{|c|c|c|c|c|c|}
\hline $\mathbf{R}$ & R2 & Adj R & $\mathbf{F}$ & Sig & \\
\hline .299 & .089 & -.366 & .196 & .701 & وجهة نظر الدمار المحاسبة القضائي القئية من \\
\hline & & $\mathbf{T}$ & Beta & Sig & \\
\hline & & .443 & .213 & .701 & Constant) \\
\hline
\end{tabular}

نلاحظ ان قيمة معامل الارتباط بين المتغيرين التابعاعداد القضايا المفصولة من وجهة نظر القضائي عموماً و المستقل

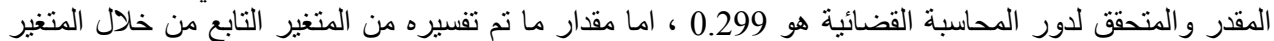

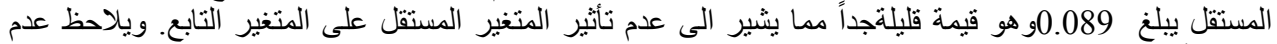

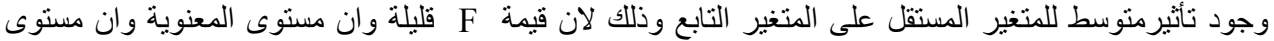

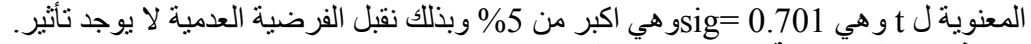
النموذج الخطي لمعادلة الانحار البسيط

$Y 1=-.327+.213 \times 3$ * معادلة خط الانحدار التي تمثل العلاقة بين المتغير المستقل X و والمتغير التابع Y فكلما زادت و واحد تزيد 0.213 بمقار 0. اختبار الفرعية الثانية للفرضية الرئيسة الثالثة:

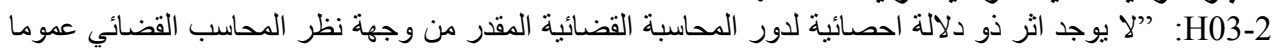
على المتحقق في قيمة القضايا الضريبية المفصولة لانة

جدول (13) العلاقة بين المقدر والمتحقى في قيم القضايا المفصولة من وجهة نظر المحاسب القضائي عموما

\begin{tabular}{|r|r|r|r|r|r|}
\hline R & R2 & Adj R & F & Sig & \\
\hline .164 & .027 & -.460 & .055 & $.836^{\mathrm{a}}$ & $\begin{array}{r}\text {. } \\
\end{array}$ \\
& & $\mathbf{T}$ & Beta & Sig & \\
\hline & & -.236 & -.096 & .836 & \\
\hline & & & & \\
\hline
\end{tabular}

نلاحظ ان قيمة معامل الارتباط بين المتغيرين التابعقيمة القضايا المفصولة من وجهة نظر المقار المحاسب القضائي عموماً

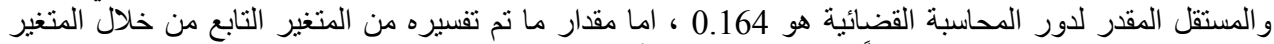

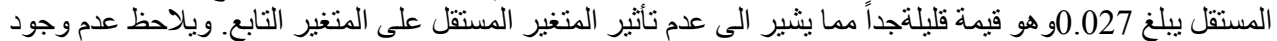

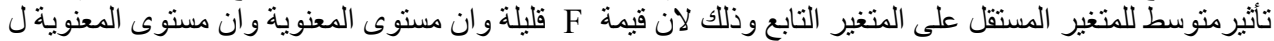

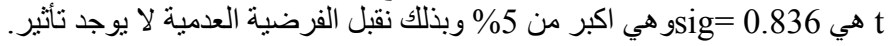


Estimations Effect of the Forensic Accounting

النموذج الخطي لمعادلة الاتحدار البسيط

$\mathrm{Y} 2=.718+-.096 \mathrm{X} 3$

* معادلة خط الانحدار التي تمثل العلاقة بين المتغير المستقل X و المتغير التابع Y فكلما زادت Xمقدار واحد تتقص

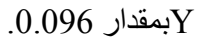

عرض وتحليل بيانات الفرضية الرئيسة الرابعة ومناقثة نتائجها:

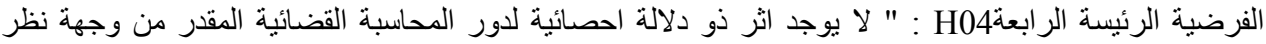

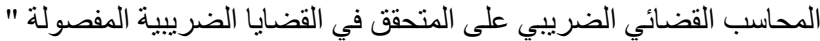
جلول (14) عرض بيانات الفرضية الرئيسية الرابعة الفيانة

\begin{tabular}{|c|c|c|c|}
\hline 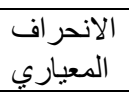 & المسابي & 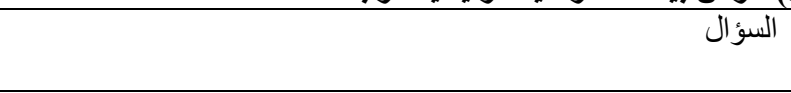 & $ت$ \\
\hline 0.53 & 4.04 & الاستقلالية في العمل & 1 \\
\hline 0.64 & 3.93 & الاقة في استخلاص النتائج & 2 \\
\hline 0.74 & 3.73 & الالتز ام بالسرية والصدق بالعمل & 3 \\
\hline 0.50 & 3.88 & الالتز ام بالنز اهة & 4 \\
\hline 0.35 & 3.91 & الالتز ام ببذل العناية المهنية اللازمة & 5 \\
\hline 0.39 & 4.03 & امتلاك مهار ات شخصية ذات طبيعة قيادية & 6 \\
\hline 0.75 & 3.99 & امتلاك مهار ات الاتصال و التو اصل بين الفئات المختلفة & 7 \\
\hline 0.92 & 3.77 & الإلمام بالإجر اءات اللازمة المتعلقة بعمليات التحري الميداني القانوني & 8 \\
\hline 0.98 & 3.67 & المعرفة و الدراية بالتطور ات المستمرة في تكنولوجيا المعلومات & $\overline{9}$ \\
\hline 0.47 & 3.89 & المعرفة و الدراية الجيدة بمستجدات أساليب التحقيق و التحري المالي & 10 \\
\hline 0.73 & 3.74 & المعرفة و الدراية الجيدة في التغير ات في قانون ضريبة الدخل والمبيعات & 11 \\
\hline 0.35 & 4.11 & توفر الخبرة الكافية في كثف التلاعب والاحتيال & 12 \\
\hline 0.32 & 3.91 & الإلمام و الخبرة الكافية في التشريعات القانونية المختلفة & 13 \\
\hline 0.89 & 3.59 & الإلمام والخبرة الكافية في النظام القضائي المعمول به في الأردن & 14 \\
\hline 0.54 & 3.97 & توفر الخبرة و الفراسة الكافية في الطبيعة الإنسانية & 15 \\
\hline 0.77 & 3.70 & القدرة على التعرف على مؤشرات السلوك الإجر امي & 16 \\
\hline 0.51 & 3.84 & امتلاك أساليب شخصية متعلقة في عملية التحقيق و التحري المالي & 17 \\
\hline 0.69 & 3.81 & القدرة على تحليل وتفسير الأرقام المالية بشكل منطقي & 18 \\
\hline 0.28 & 3.94 & القدرة على حل النز اعات التي تتتج عن التحريات و النقاش & 19 \\
\hline 0.57 & 3.90 & سر عة البديهة و الاستجابة للأحداث المستجدة & 20 \\
\hline 0.11 & 4.07 & 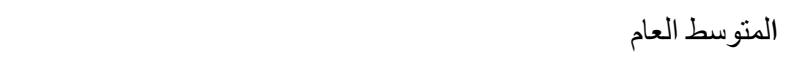 & \\
\hline
\end{tabular}




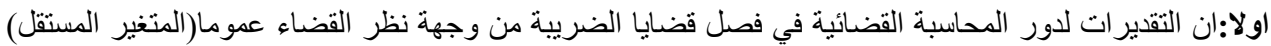

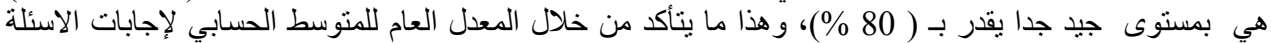

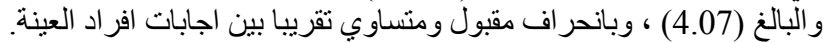
ثانيا: تحليل البيانات الكمية (المتغير التابع) يبين:

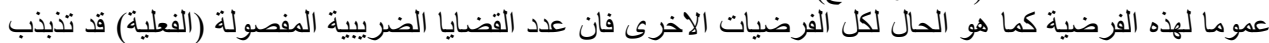

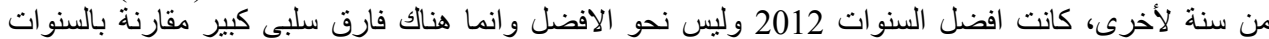

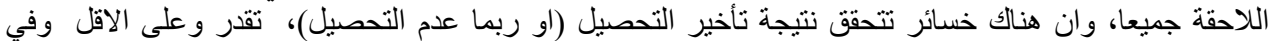
احسن الاحو ال بمعدل 1607 ملف سنويا، و هذا يعادل حوالي 37 \% من معدل الملفات السنوية الكلية، و هذه المعلومات الات تصح لكل فرضيات الدراسة. تحليل البيانات على اساس كل فرضيات الراسة:

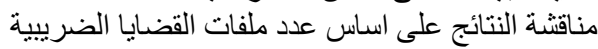

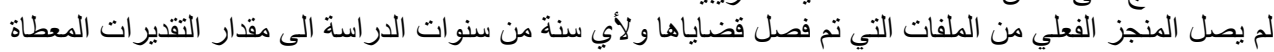

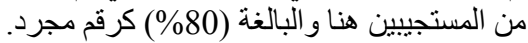

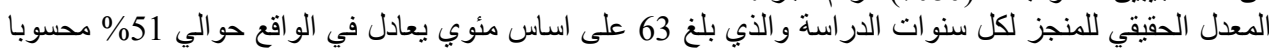

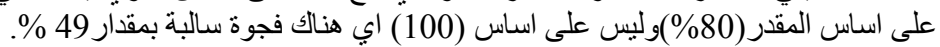

مناقشة النتائجعلى اساس قيم(دينار ) القضايا الضريبية

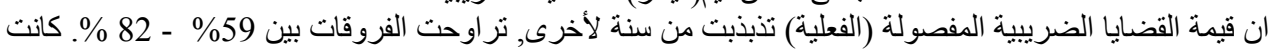

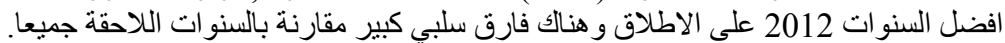

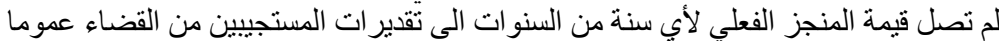
المعدل للمنجز لكل سنوات الدراسة بلغ 33 \% \% ، اي هناك فجوة بمقدار 67 \% \% كنسبة مئوية. اما مقارنة بالمقدر (80)

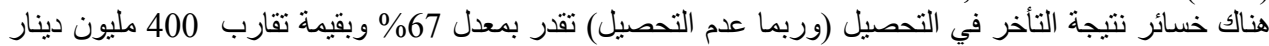

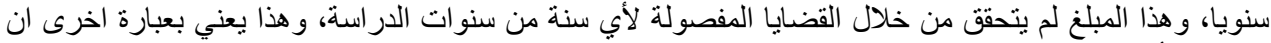
الخسائر تأخذ شكل تر اكمي. ولتقييم اثر هذه النتائج التقديرات (المتغيرات المستقلة)على المتحقق فعلا في فصل القضايا الضريبية (المتغيرات

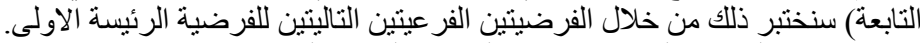

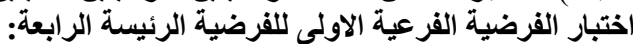

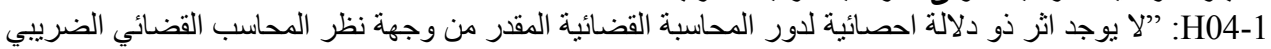

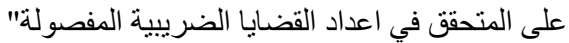

جدول (15) العلاقة بين المقدر والمتحقق في اعداد القضايا المفصولة من وجهة نظر المحاسب القضائي

\begin{tabular}{|r|r|r|r|r|r|}
\hline R & R2 & Adj R & F & Sig & \\
\hline .466 & .217 & -.174 & .556 & .534 & $\begin{array}{r}\text { و } \\
\end{array}$ \\
& & T & Beta & Sig & \\
\hline & & .746 & .472 & .534 & \\
\hline
\end{tabular}

نلاحظ ان قيمة معامل الارتباط بين المتغيرين التابعاعداد القضايا المفصولة من وجهة نظر المحاسب القضائي

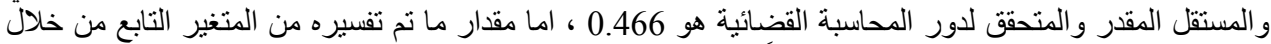

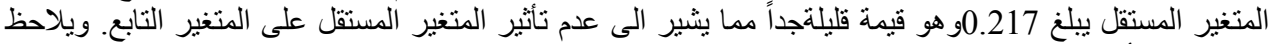

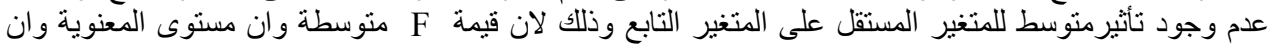

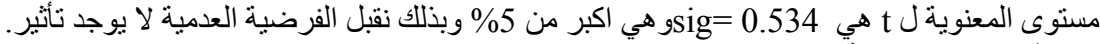

النموذج الخطي لمعادلة الانحدار البسيط

$Y 1=-1.29+.472 X 4$ 
* معادلة خط الانحدار التي تمثل العلاقة بين المتغير المستقل X و المتغير التنابع Y فكلما زادت و واحد تزيد

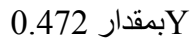

اختبار الفرضية الفرعية الثانية للفرضية الرئيسة الرابعة: H04-2

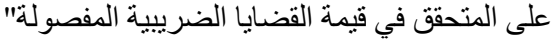

جدول (16) العلاقة بين المقدر والمتحقى في قيم القضايا المفصولة من وجهة نظر المحاسب القضائي

\begin{tabular}{|c|c|c|c|c|c|}
\hline $\mathbf{R}$ & R2 & Adj R & F & Sig & \\
\hline \multirow[t]{3}{*}{.209} & .044 & -.435 & .091. & .791 & وجهة نظر الدحاسب القضائية القيائية من \\
\hline & & $\mathbf{T}$ & Beta & Sig & \\
\hline & & .173 & .302 & .791 & \\
\hline
\end{tabular}

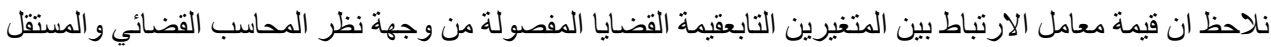

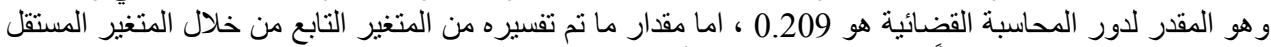

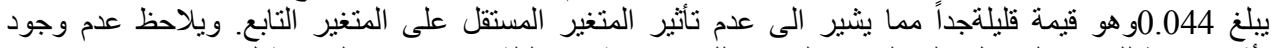

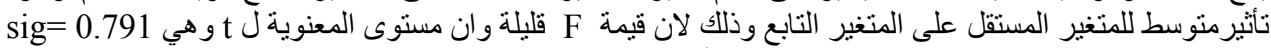
اكبر من 5\% و وبذلك نقبل الفرضية العدمية لا يوجد التأثير.

النموذج الخطي لمعادلة الانحدار البسيط لغرضي

$Y 2=-.349+.173 \times 4$

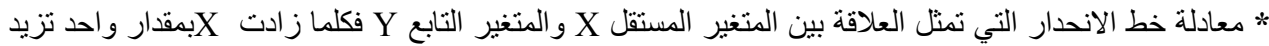

0.173 بمقاد 0.

خلاصة النتائج

هناك تطابق كبير يكاد يكون كلي بين اراء المستجيبين حول تقديرات دور المحاسبة القضائية في فصل القضايا

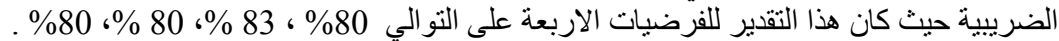

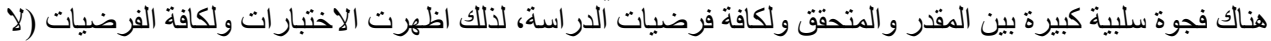

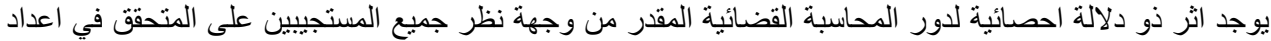

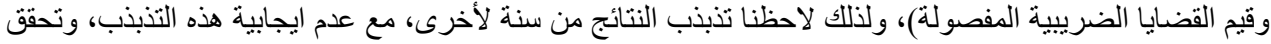

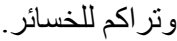

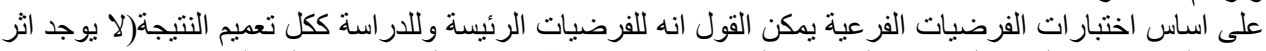

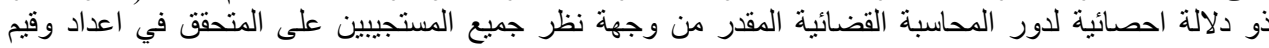

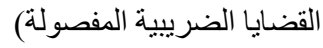

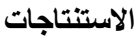

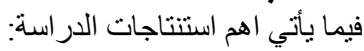

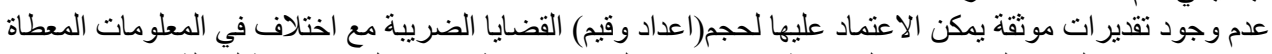

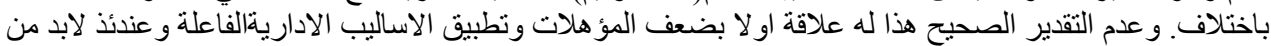

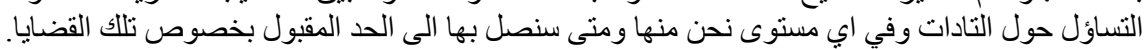

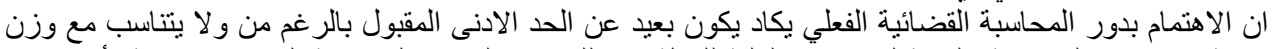

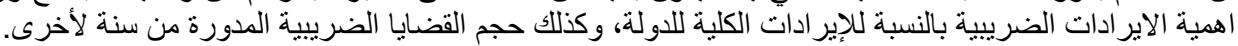

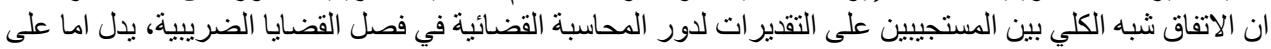

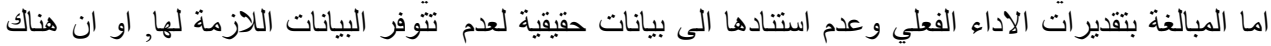
اخفاقات في الانجاز الفعلي.

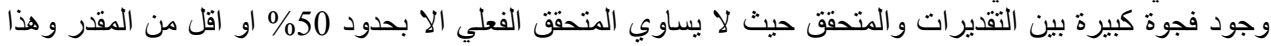

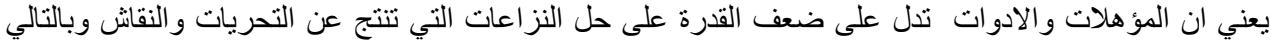

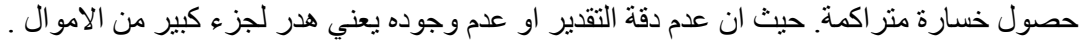


ـالتوصيات

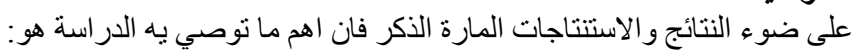

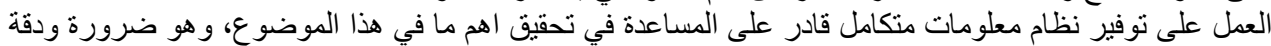

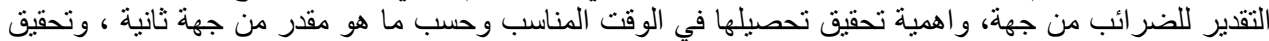
العدالة في التحصيل من جهة ثنالثة. الاهنمام بدور المحاسبة القضائية في الاداء الضريبي لمواجهة التزايد في حجم القضايا غير المفصولة وتحقيق العدالة لكل الاطر اف. نشر معلومات كافية عن الضريبة وقضاياها و المفصول و المتأخر وتبويبها حسب اسبابها الرئيسة لفتح مجال اكبر امام الرقابة والبحث العلمي الهادف وإجراء الجية المزيد من الدراسات والبحوث في فوضي موضوع المحاسبة القضائية لتدعيم ممارساتها في ميدان التطبيق العملي في فصل التصل القضايا الضريبية.

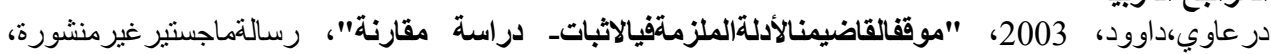

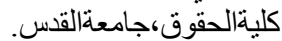

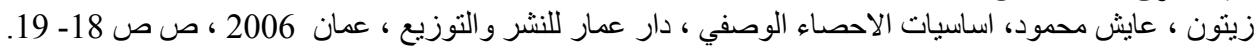

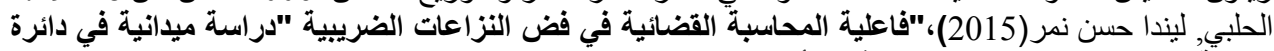

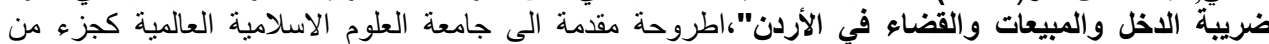

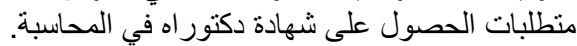

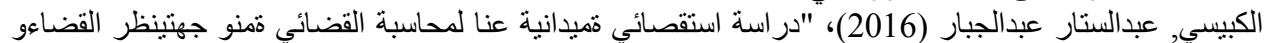

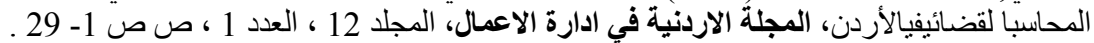

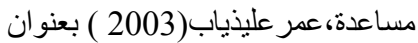

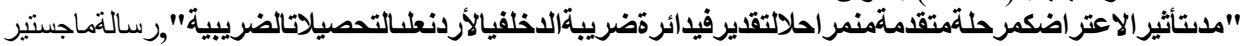

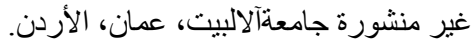

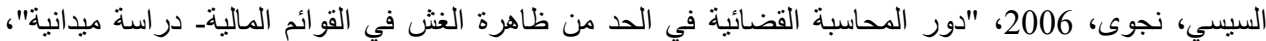

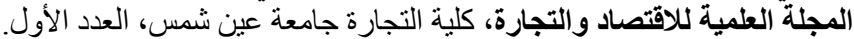

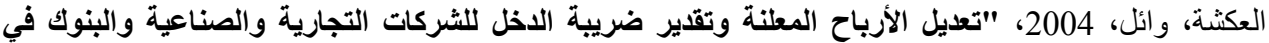

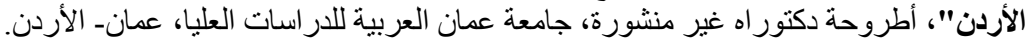

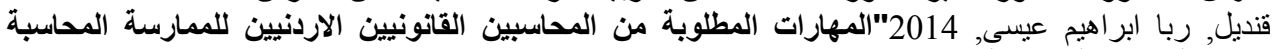

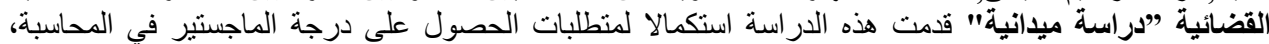

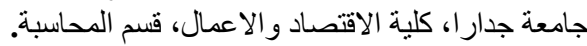

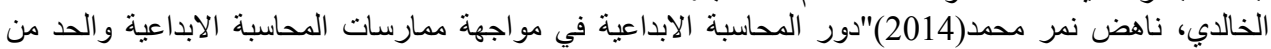

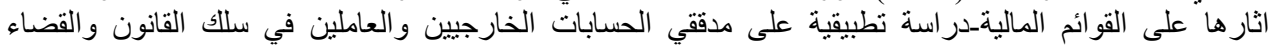

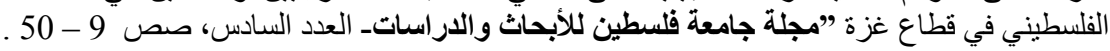

المراجع باللغة الانكليزية

1. Brennan, Niamh (2005), Accounting Expertise in Litigation and Dispute Resolution, Journal of Forensic Accounting,Vol.VI, R.T. Edwards, Inc., Printed in U.S.A. pp. 333-356.

2. Crumbley, Larry, Forensic Accounting: Older Than You Think, Journal of Forensic Accounting, Vol.II(2001), (C 2001 R.T. Edwards, Inc., Printed in U.S.A., pp. 181-202.

3. Crumbley, Larry and Apostolou, Nick(2001),"Cooking The Books And You Will Go Directly To Jail Without Passing Go1,Journal of Forensic Accounting, Vol. II, R.T. Edwards, Inc., Printed in U.S.A., pp.131-138.

4. Huefner, Ronald J.(2010)."The Forensic Audit: An Example from the Public Sector", Journal of Forensic \& Investigative Accounting,Vol.2, Issue 1, ,PP1-16.

5. KesslerNews, November1, ， com/article/library/2001 articles.http://www.Investigation 
6. Muehlmann, Brigitte W. and Burnaby, Priscilla and Howe, Martha, (2012)," The Use of Forensic Accounting Experts in Tax Cases as Identified in Court Opinions", Journal of Forensic \& Investigative Accounting, Vol. 4, Issue 2, Pp. 1- 34.

7. Muehlmann Brigitte W. and Priscilla A. Burnaby(2015), "Masters in Federal Tax Cases The Role of Special as Identified in Court Opinions"Journal of Forensic \& Investigative Accounting, Vol. 7, Issue 2, July - December pp1-30

8. Nunn, Les; McGuire, Brian L.; Whitcomb, Carrie; Jost, Eric, (2006), "Forensic Accountants: Financial Investigators"; Journal of Business \& Economics Research February Volume4.

9. Okoye, E.I. \& D.O. Gbegi، (2013) "Forensic Accounting: A Tool for Fraud detection and Prevention in the Public Sector. (A Study of Selected Ministries in Kogi State)" International Journal of Academic Research in Business and Social Science", Vol. 3 No.4, ISSN: 2222-6990 (www.hrmars.com).

10. Ole-Kristian Hope, Mark (Shuai) Ma and Wayne B. Thomas (2013)," Tax Avoidance and Geographic Earnings Disclosure" Rotman School of Management University of Toronto May 28,Pp. 1-52, http://ssrn.com/abstract=2021157

11. Okoye, Emma Lk(2009):’The Role Of Forensic Accounting In Fraud Investigation And Litigation Support" Nnamdi Azikiwe University-Department Of Accountancy Vol.17 ,No.1 ,November.

12. Osborn, John(2007),"The Usefulness of Fraud Warning Signs in Forensic Accounting, Journal of Forensic Accounting, Vol.VIII, R.T. Edwards, Inc., Printed in U.S.A. , pp. 335-346

13. Owojori, A.A, and Asaolu, T. O. , (2009)"The Role of Forensic Accounting in Solving the Vexed Problem of Corporate World", European Journal of Scientific Research, ISSN 1450-216X Vol.29 No.2, (C) Euro Journals Publishing, Inc. , pp.183-187.

14. Ramaswamy, Vinita, (2007), "New Frontiers: Training Forensic Accountants within the Accounting Program", University of St. Thomas Houston, Journal of College Teaching \& Learning,volume4, PP. 31- 38.

15. Sanchez Maria H.and Zhang Shirley Wei (2012),"THE ROLE OF THE EXPERT WITNESS IN ACCOUNTING FRAUD CASES" GLOBAL JOURNAL OF BUSINESS RESEARCH , VOLUME 6, NUMBER 1 ,Pp. 103 - 111 